\title{
تذاخل الأنواع الأدبية في أدب المذكرات
}

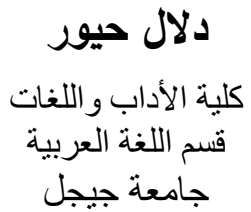

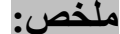

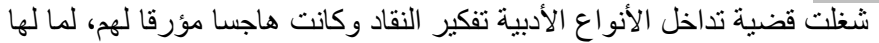

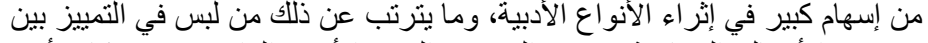

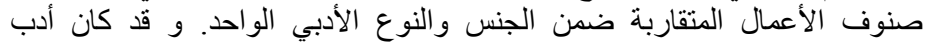

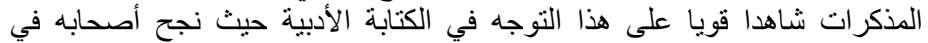

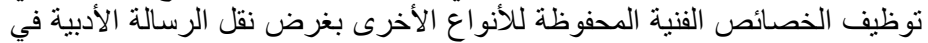

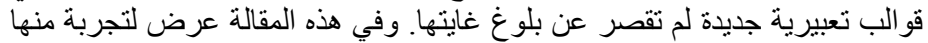

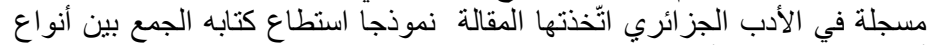

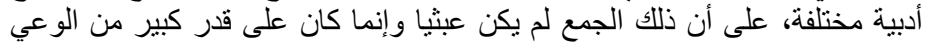

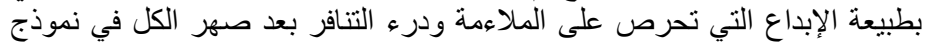

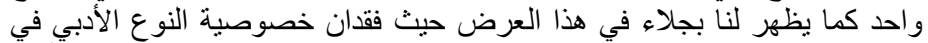

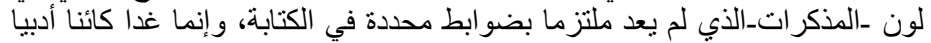

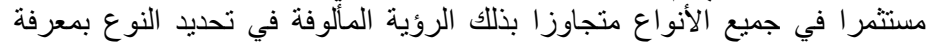

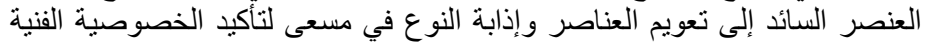

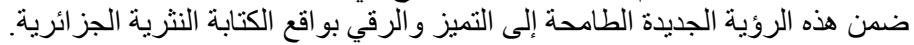

$$
\text { الكلمات المفتاحية: تداخل الأجناس الأدبية ـأدب المذكر ات_اليوميات ـالرواية }
$$

\begin{abstract}
:
The issue of literary genres overlaphas concerned critics' thinkingtoobsession due to its contribution to the enrichment of literary genres, resulting in the confusion that characterizes many comparable works within the same category or genre. The literature of memoirshas been a genre in which their ownershave excelled in transferringtheir messages in newliterary templates employing thereinwhat ofagreement and harmonyfrom other literary genres. Thisarticlehas adopted an Algerian literary model whose writers have beenable to combine different genres. Such a combinationis not useless as much as it relies on what makes these genres converge, despite each type would necessarily take hold of what would distinguish it, especially in the techniques used.Also evident in this kind of article is the loss of the specificity of the genre-memoir-which is no longer bound to specific standards in writing but all other genres, whether similar to each other or different from the general type, have become available for employment, because their presence in the literary work has turned into a specific feature of its author, who tends to develop what is newin the world of Algerianprose writing.
\end{abstract}


"يعبر عن تجاربه الثخصية بأنشكال مختلفة، وأي شكل يتبناه يحتم عليه إعادة تشخيص حياته وتشغيل

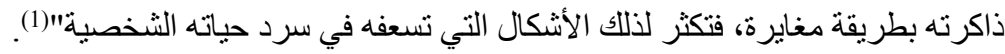

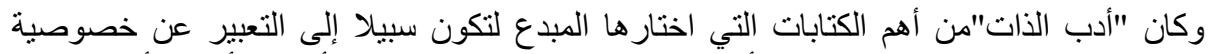

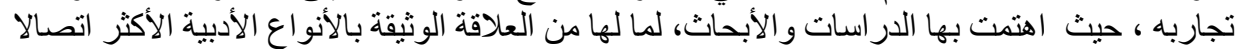

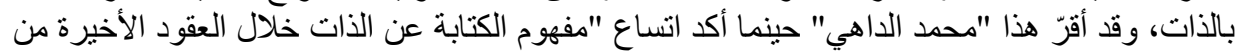

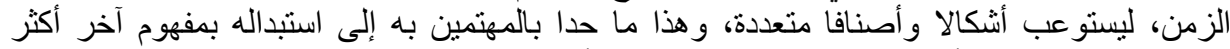

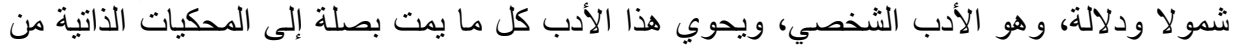

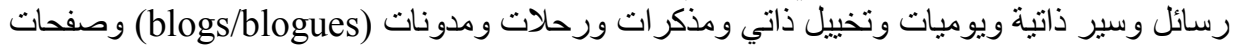

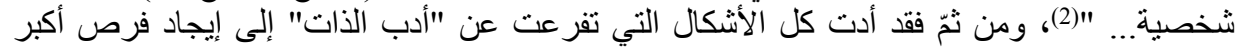

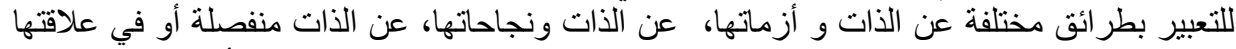
بمجموع الذوات المتفاعلات معها في المشهد الاجتماعي الذي يمنحها الوجود المميز أو الناجح في نهاية

لقد شكل أدب الذات فسحة، وجد فيها الكاتب حرية أكبر لعرض انشغالاته، ومعاناته الفردية بطرق الأمر

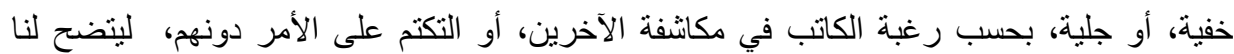

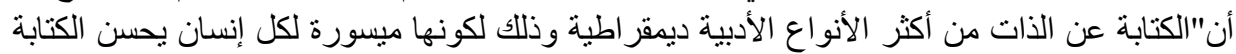
ويجد الرغبة في رواية الذكريات الشخصية. إن كل البشر، على الخت اختلاف مستوياتهم الثقافية والتعليمية

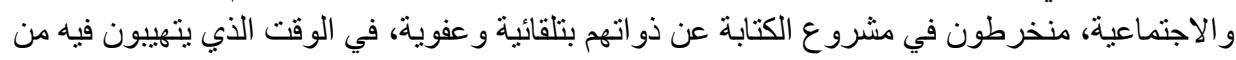

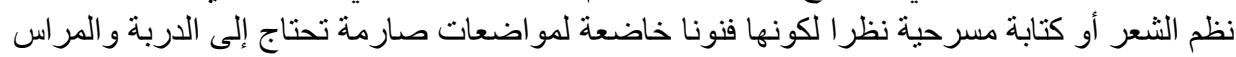

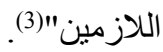

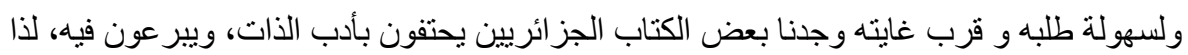
سنحاول الوقوف عند أحد أنو اعه وهو "المذكرات" لغرض وجن مقاربة الإشكال العالق بهذا النوع من الكتابة

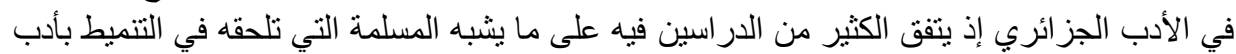

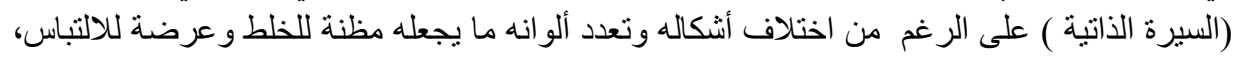
ويصعب من عملية استجلاء مميزاته وخصائصه" (4)، فما حقيقة هذا المعطى المسبق الذي التي اتفق عليه

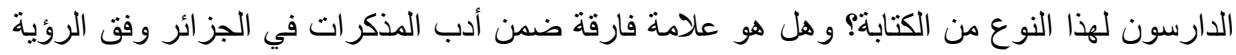

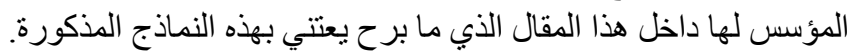

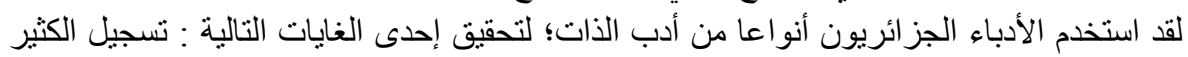

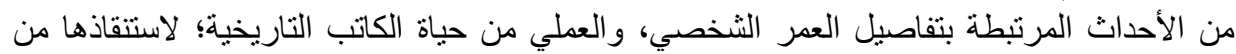

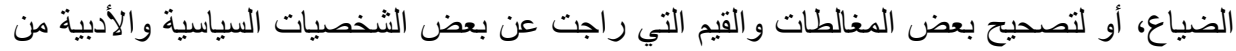

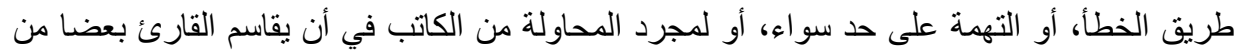

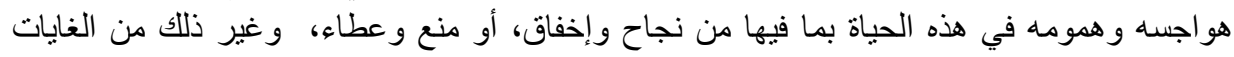
و الدو افع التي أفضت إلى الكتابة في نوع"المذكرات" مثلما سنوضحه في النقطة الأساسية التي تتمحور

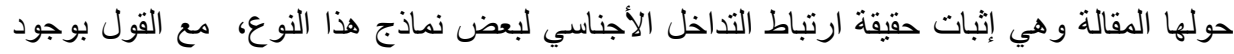

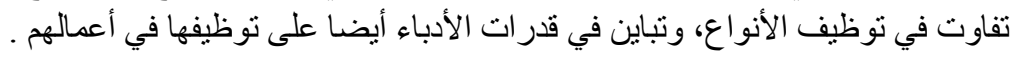

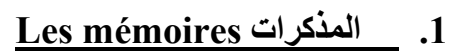

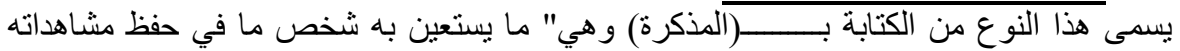

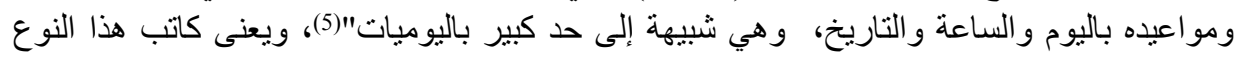

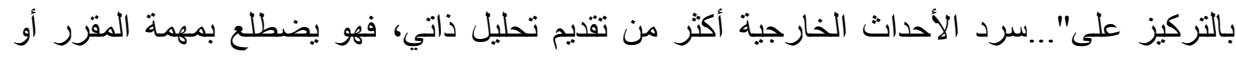


الإخباري الذي يحرص على عرض أحداث معينة بدافع الثهادة، وتعليل الفعل أو القول بعد حصولهما،

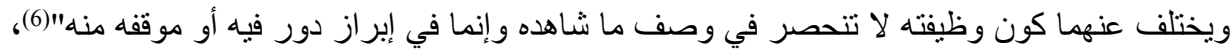

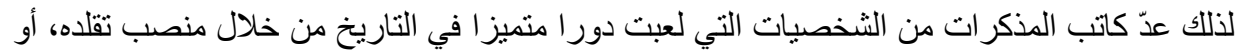

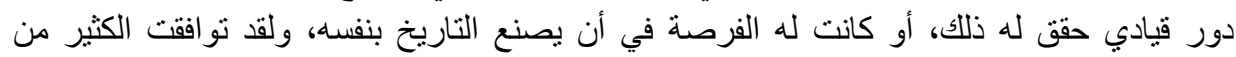

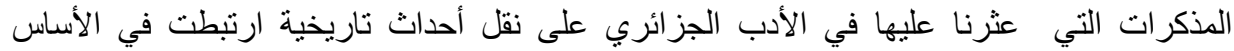

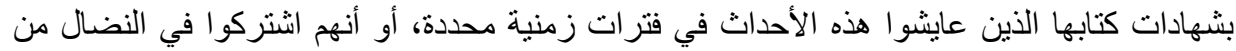

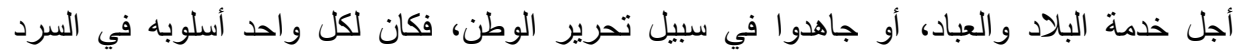

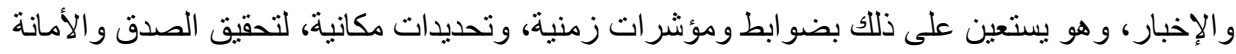

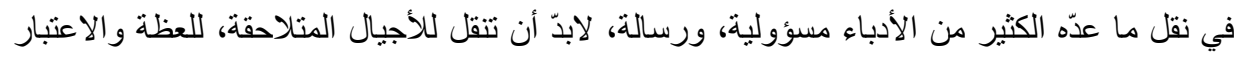

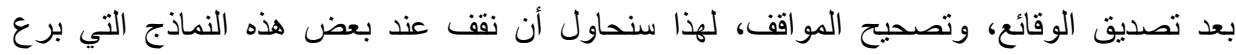

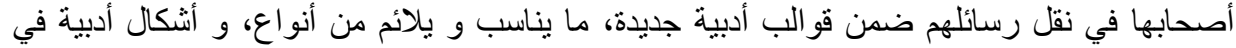
نسيج الدذكرات بوصفها نو عا أصليا.

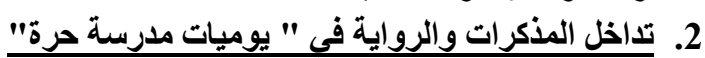

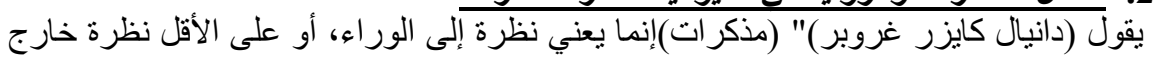

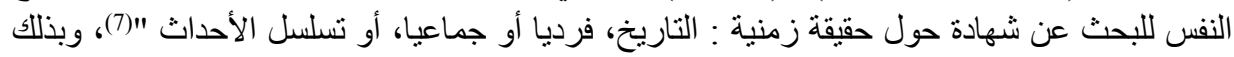

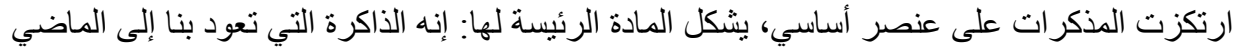

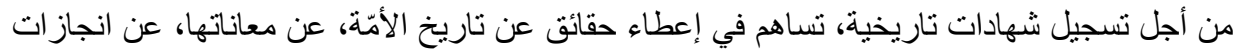

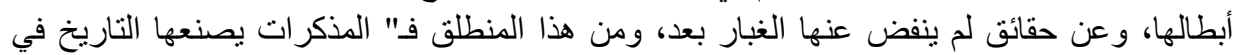

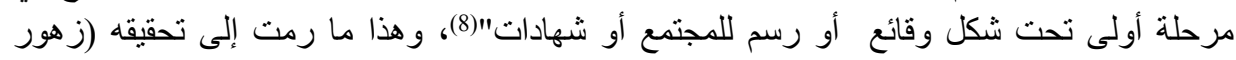

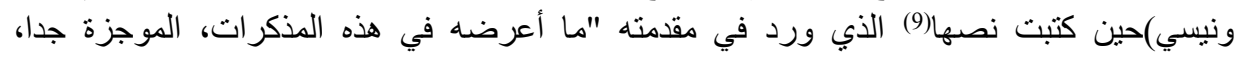

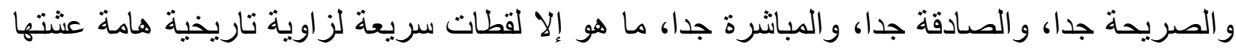

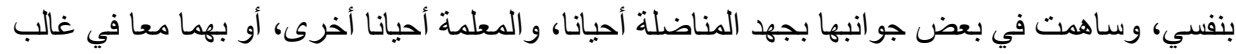

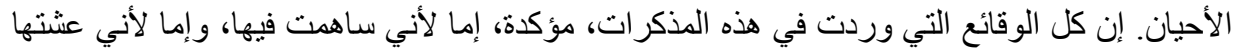

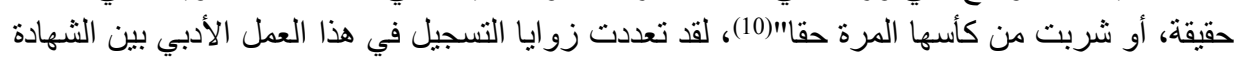

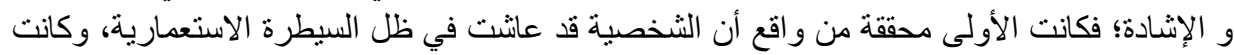

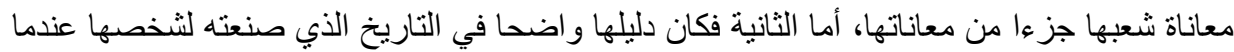

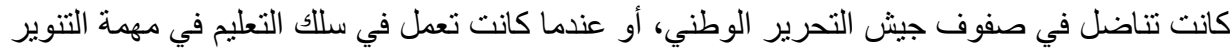

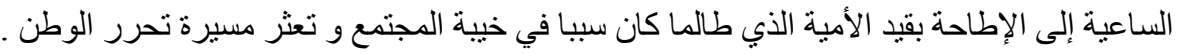

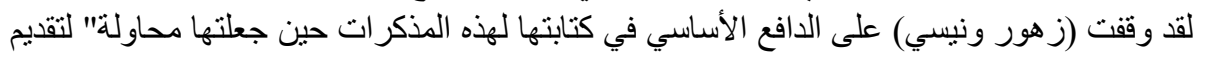

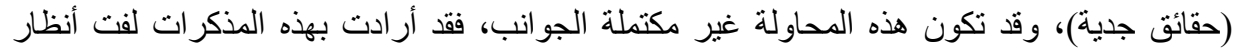

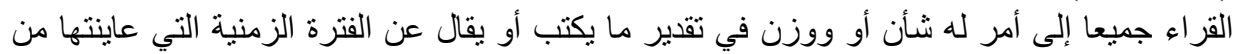

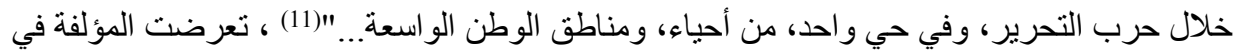

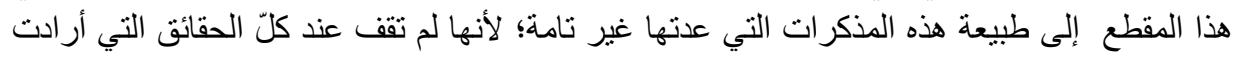

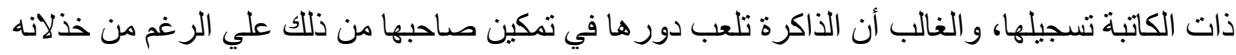

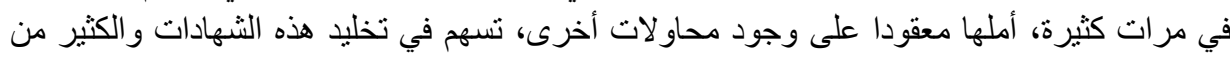




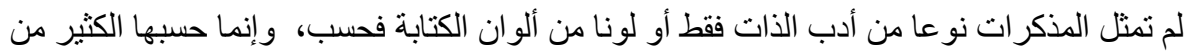

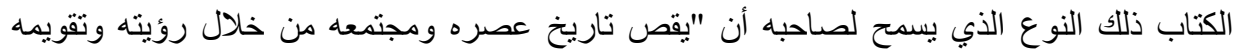

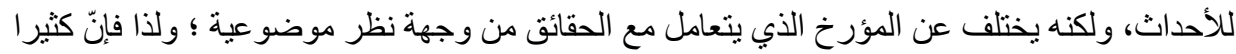

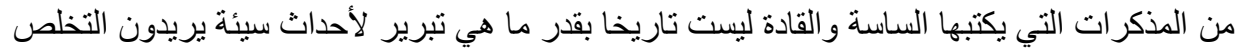

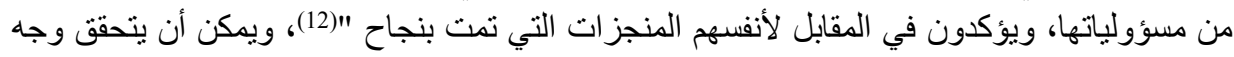

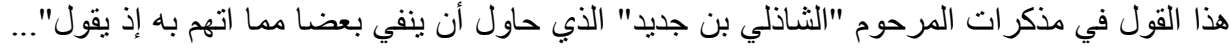

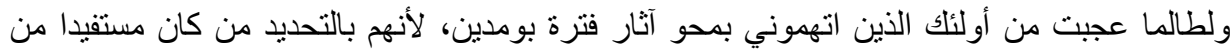

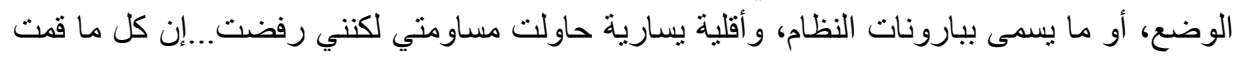

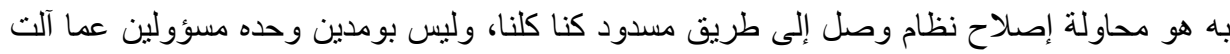

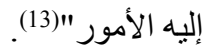

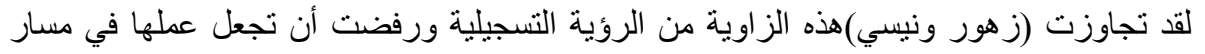

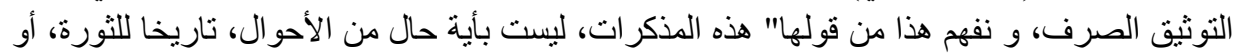

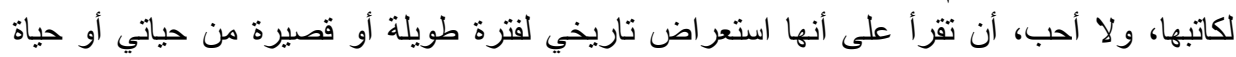

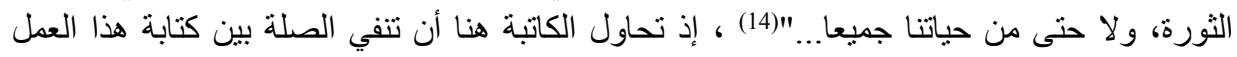

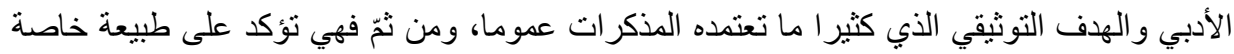

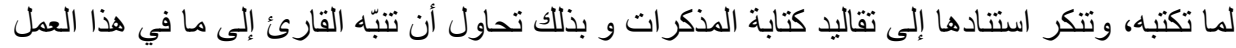

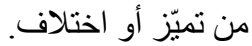

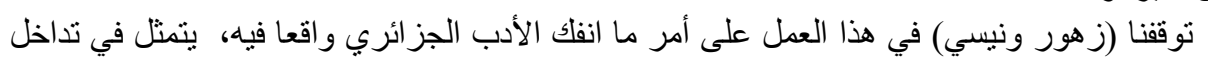

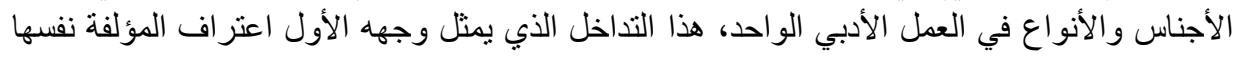

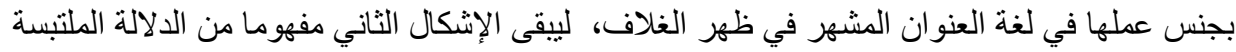

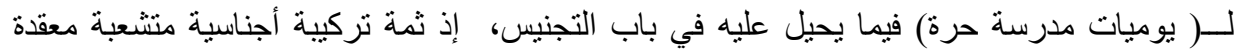

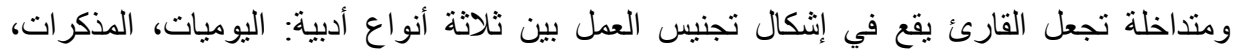

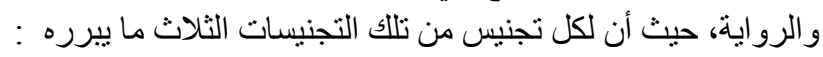

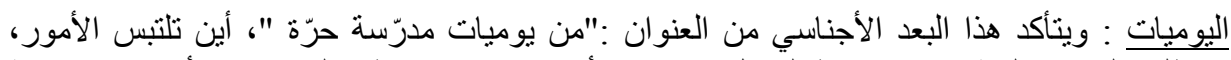

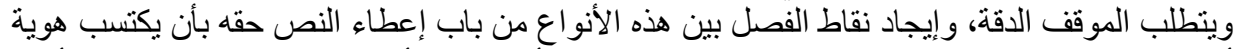

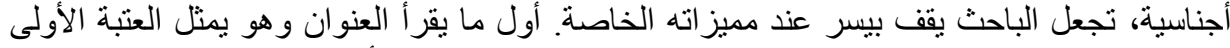

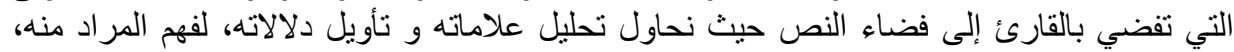

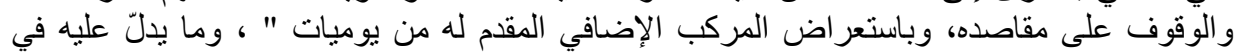

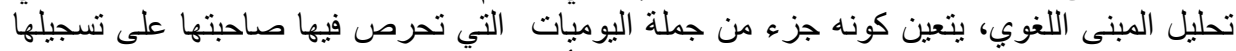

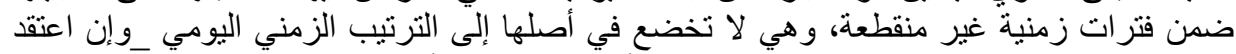

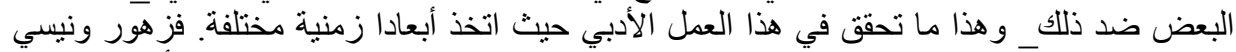

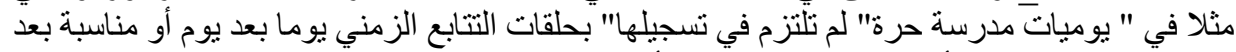

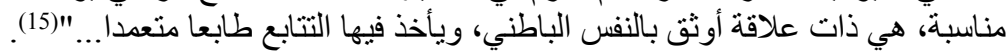

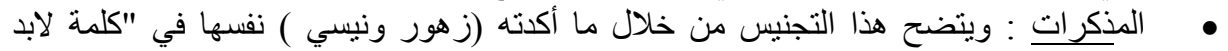

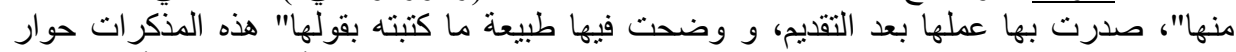

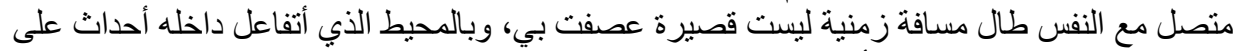

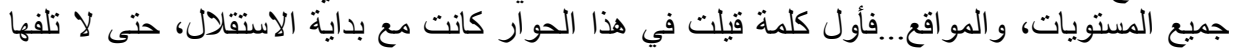

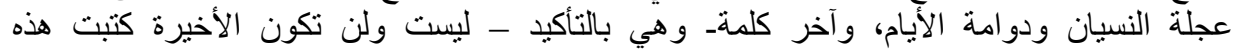

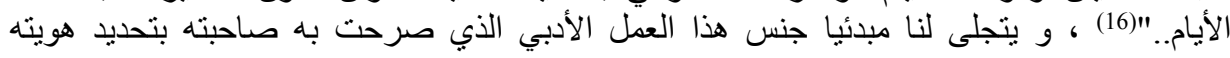


الأجناسية وتصنيفها ضمن ( المذكرات)، غير أننا نقف عند نقطة، يثير ها تجنيس النص هي: أن هذه أنها

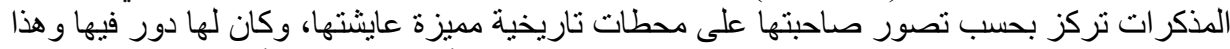

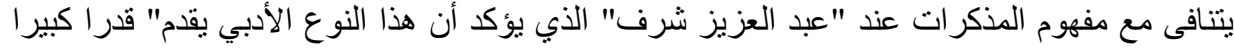

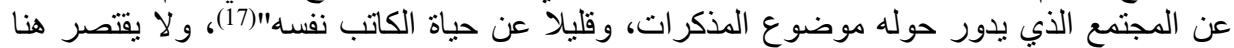

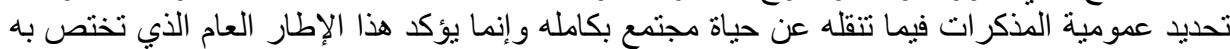

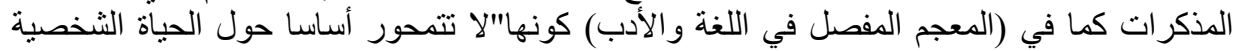

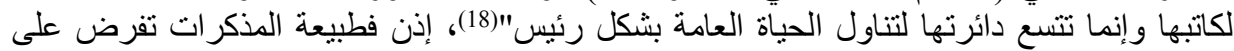

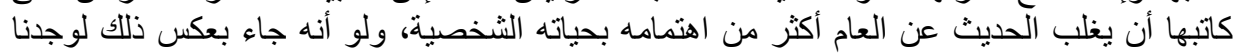

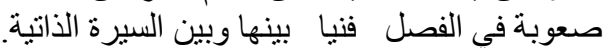

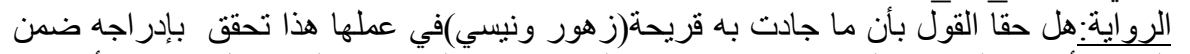

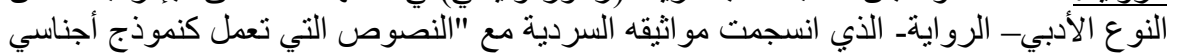

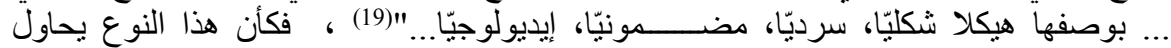

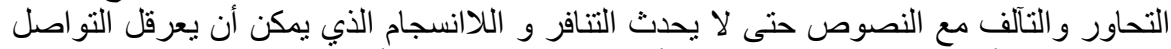

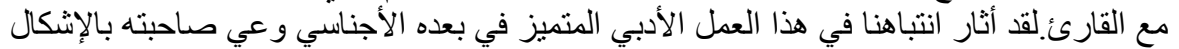

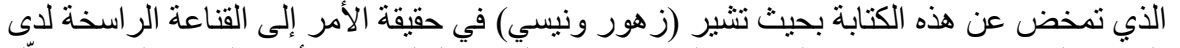

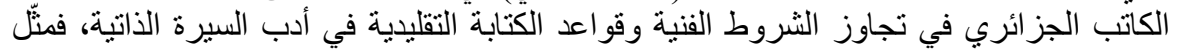

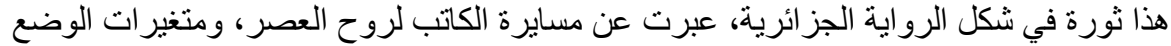

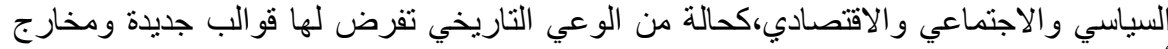

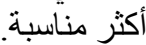

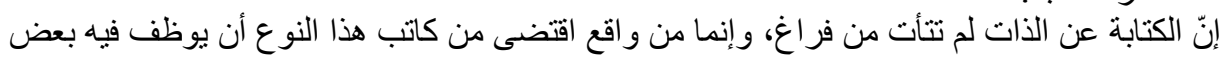

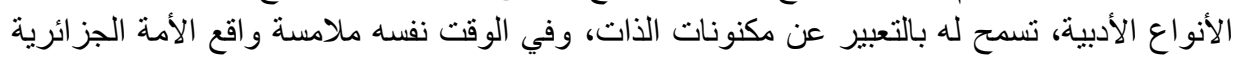

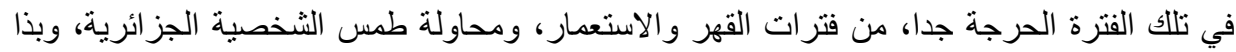

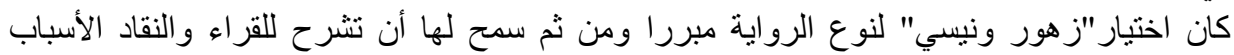

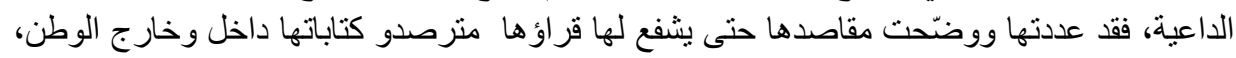

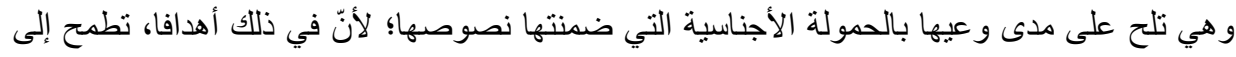

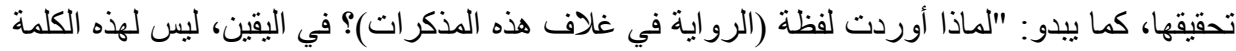

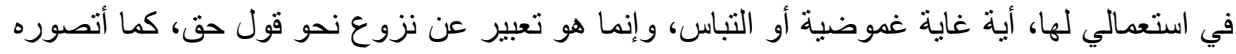

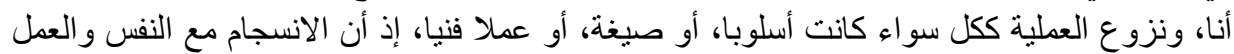

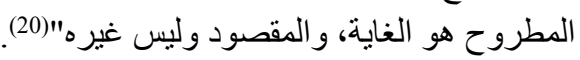

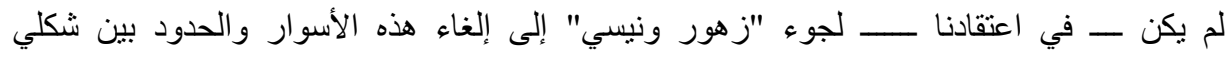

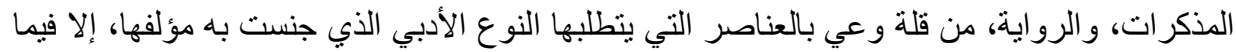

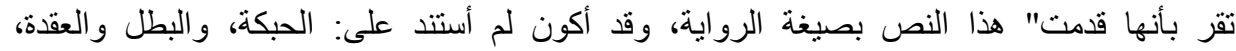

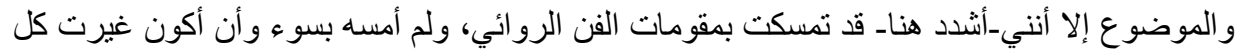

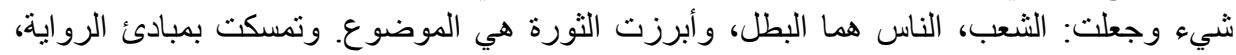

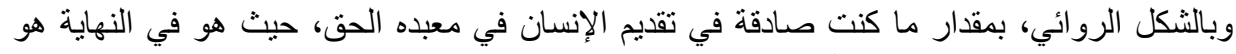

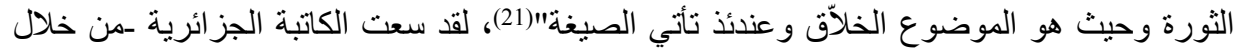

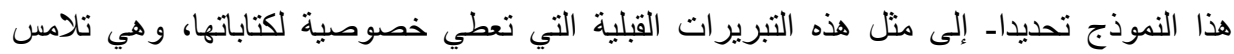

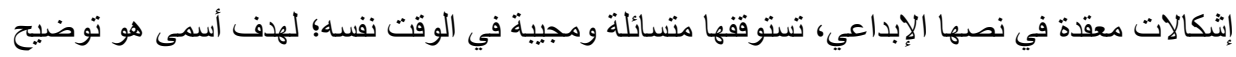

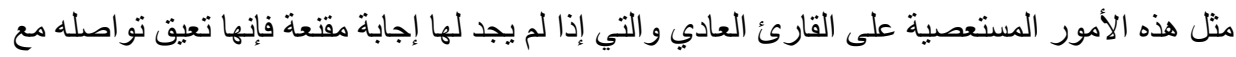




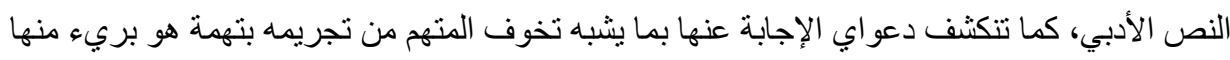

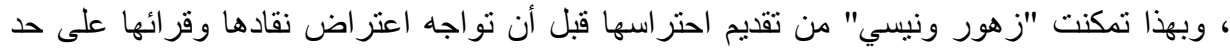
سواء.

ومما سبق إير اده حول إثكالية تجنيس نص "من يوميات مدرسة حرّة" فإن القارئ يستقبله على أنه

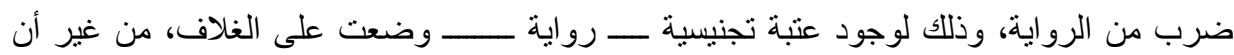

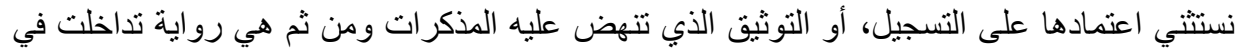

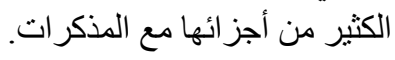

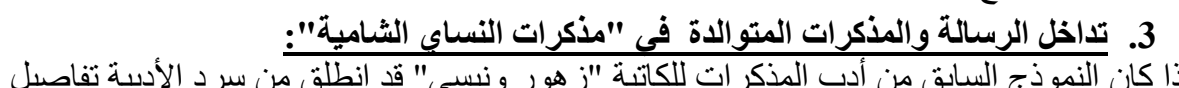

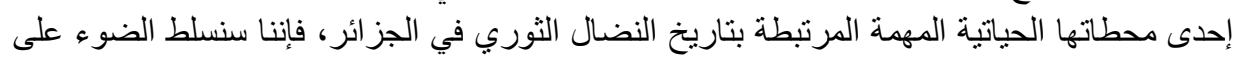

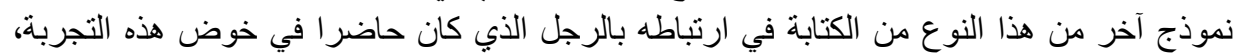

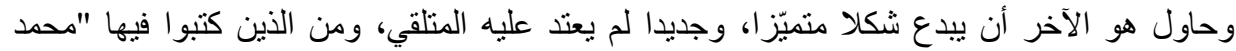

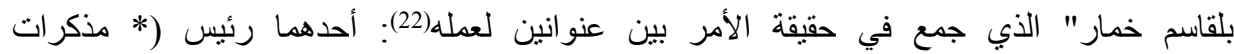

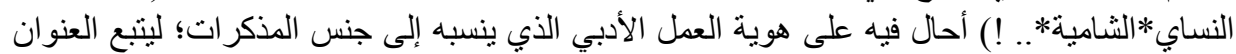

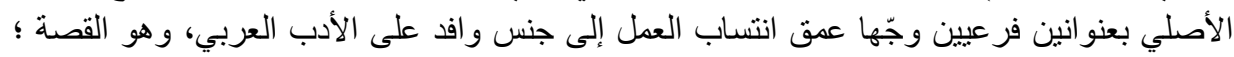

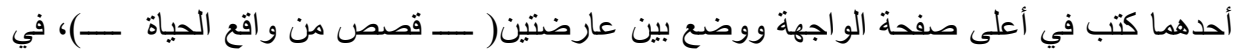

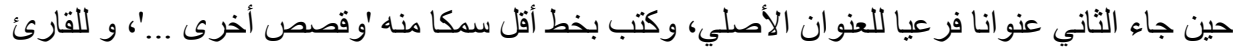

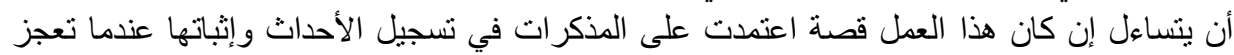

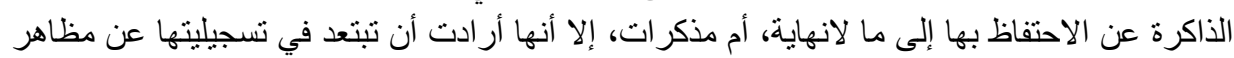

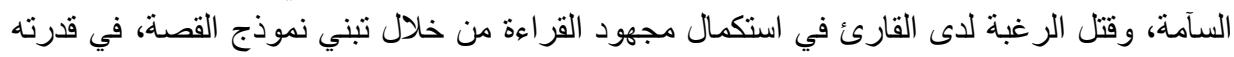

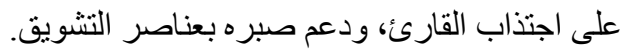

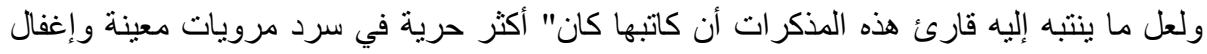

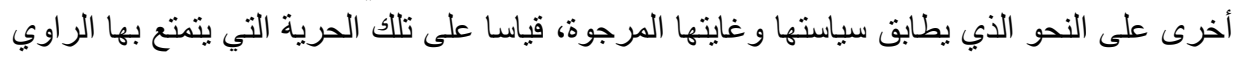

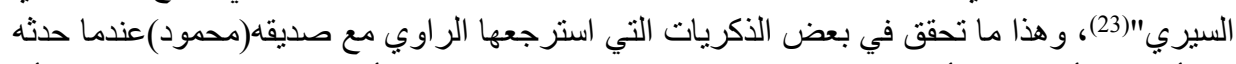

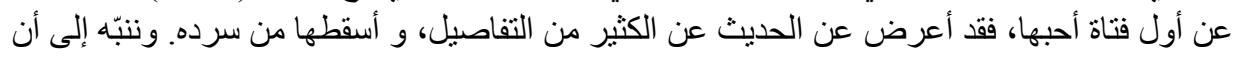

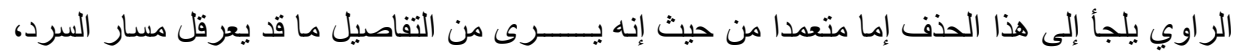

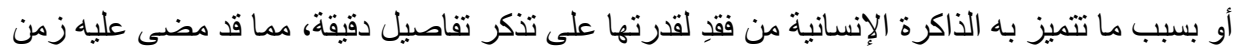

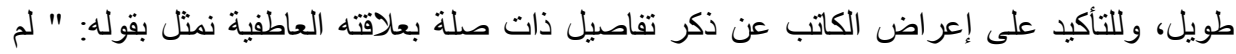

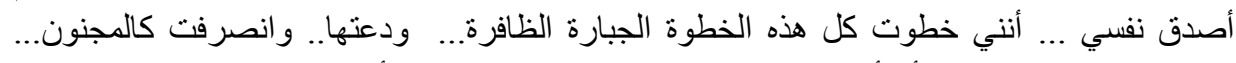

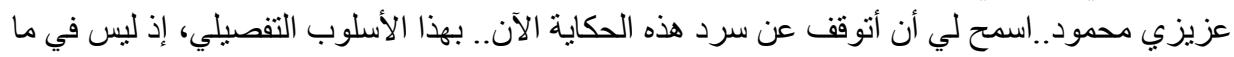

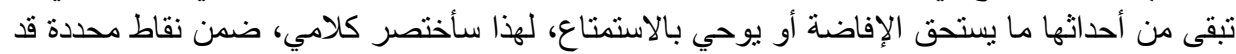

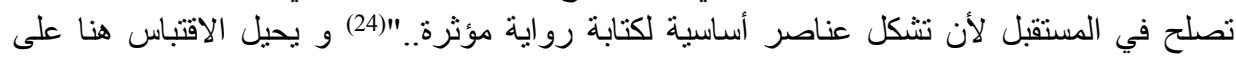

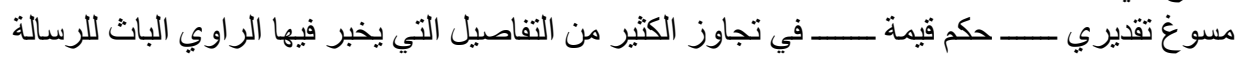

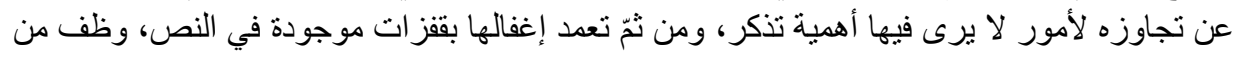

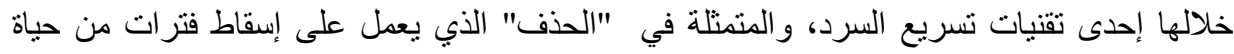
الثخصية، أو الققز على بعضها. 
إن ما يستوقفنا أيضا في هذا العمل هو الجمع بين جهدين، أرغمت عليهما الذات الكاتبة؛ أولهما التذكر

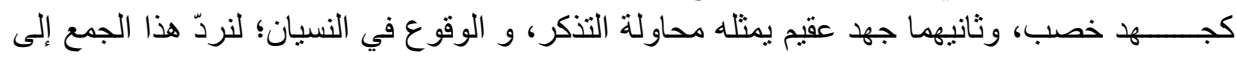

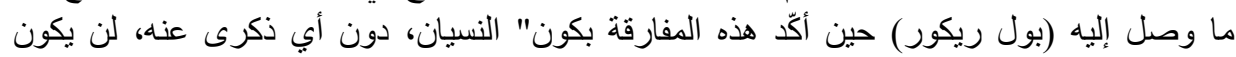

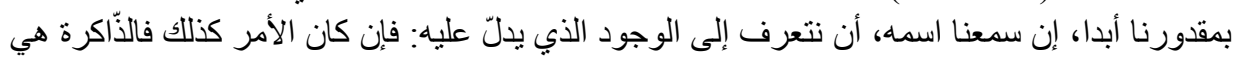

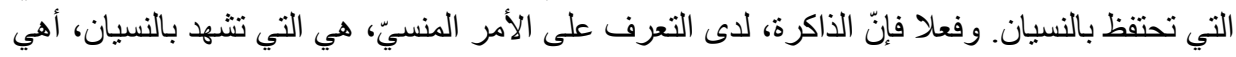

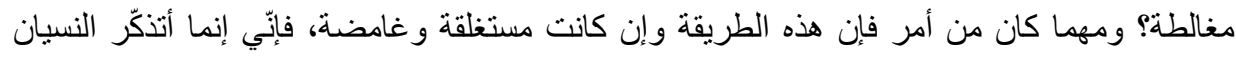

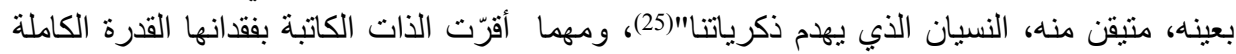

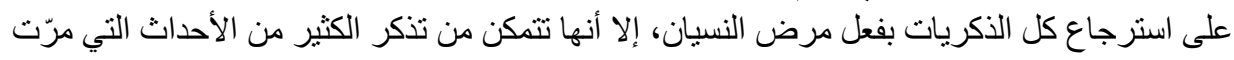

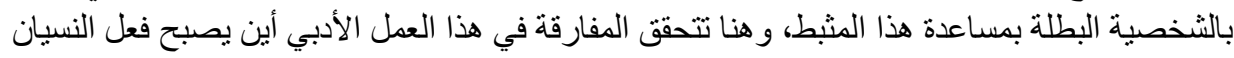

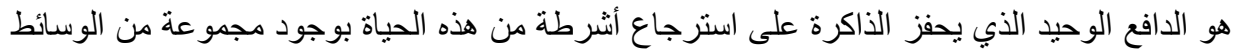

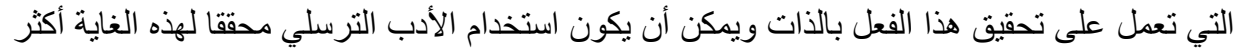

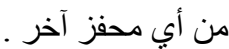

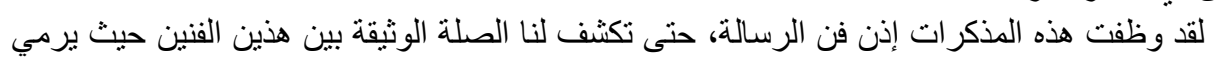

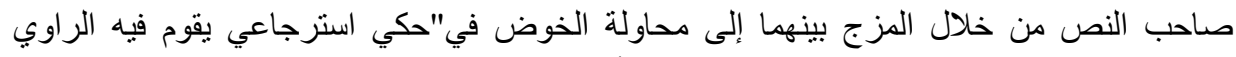

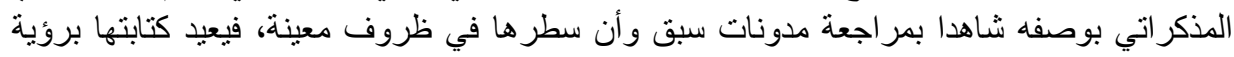

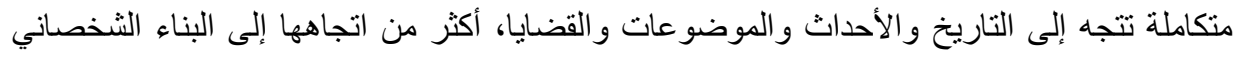

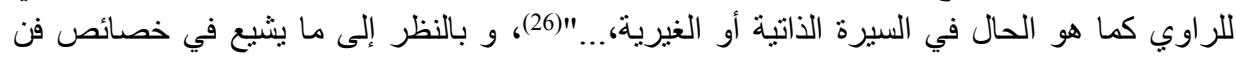

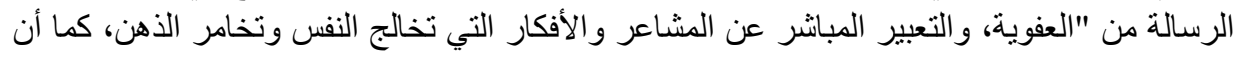

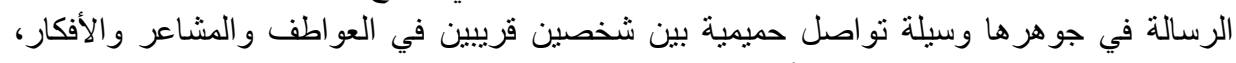

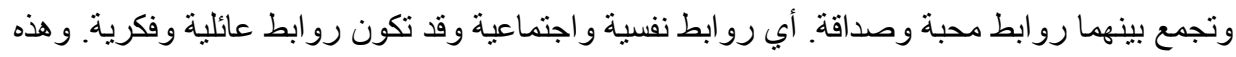

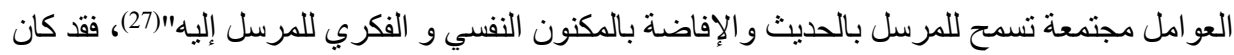

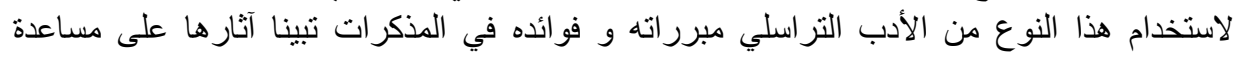

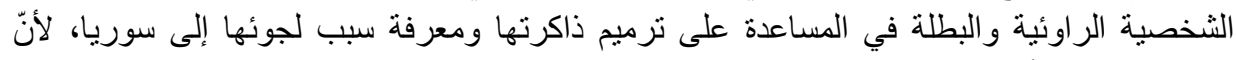

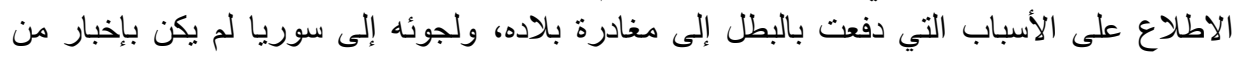

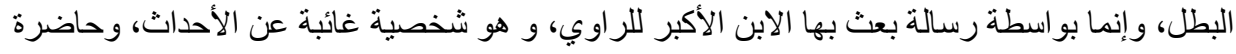

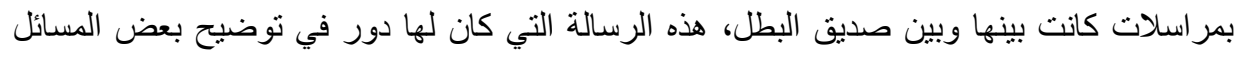

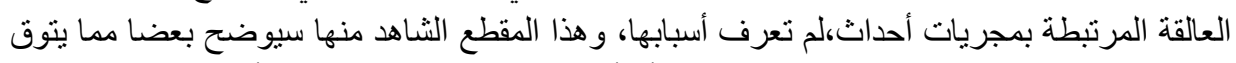

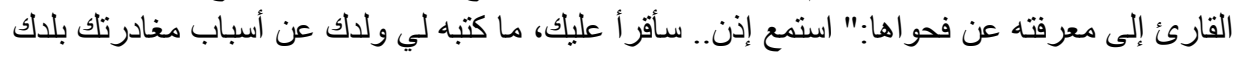

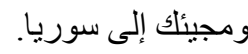
يقول ولدك الأكبر :" لقد كنا جميعا نعلم بأن و الدنا مريض بداء النسيان، وذلك منذ سنين طويلة. وكنا

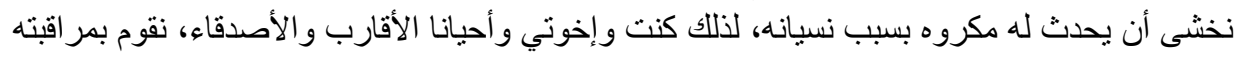

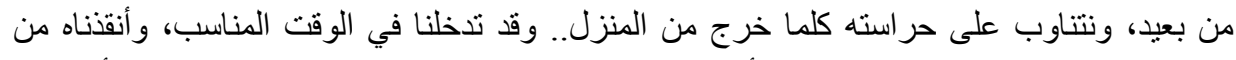

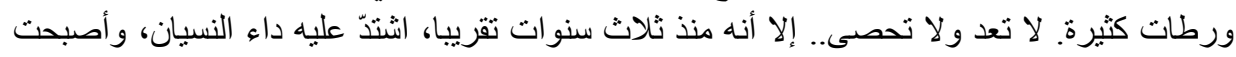

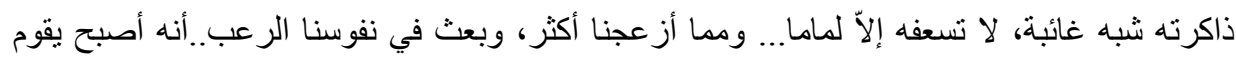

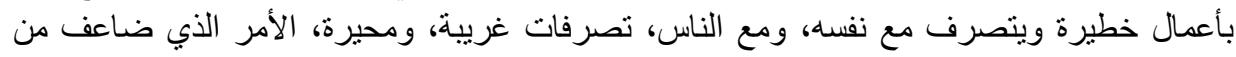

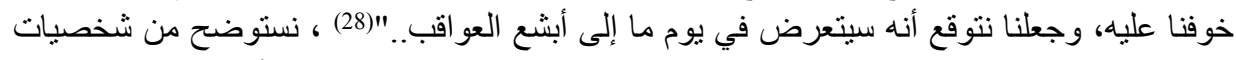

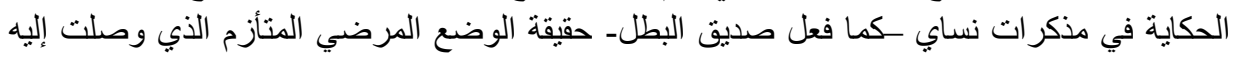




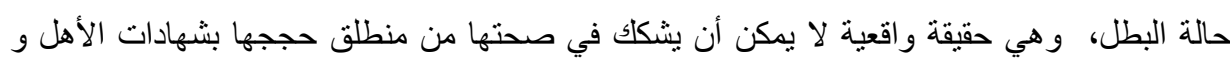

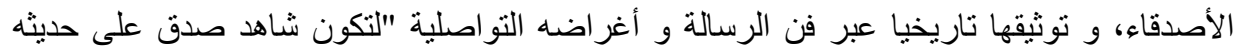

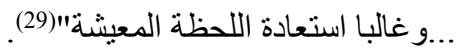
لقد اعتمت هذه الدذكرات على تقنية من تقنيات المفارقة السردية، لها وظيفة إبطاء وتيرة السرد،

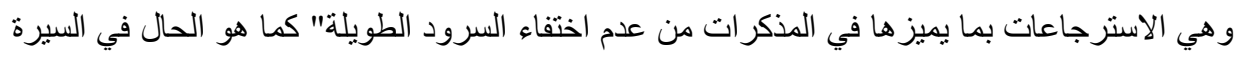

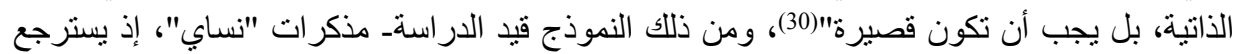

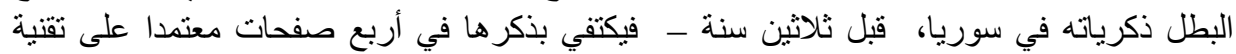

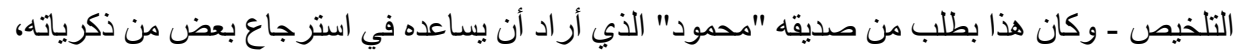

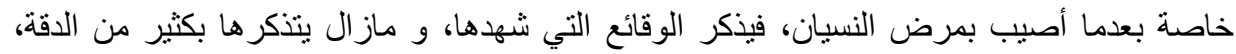

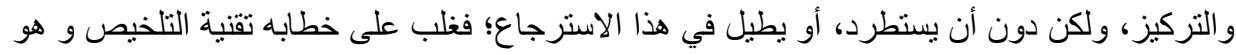

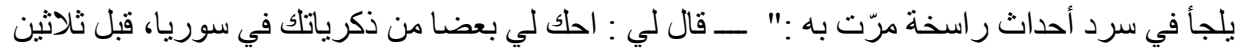

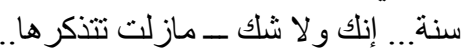

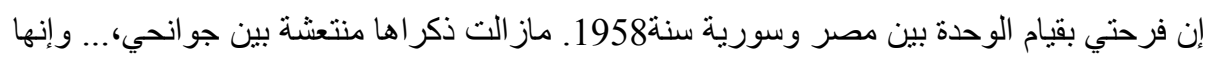

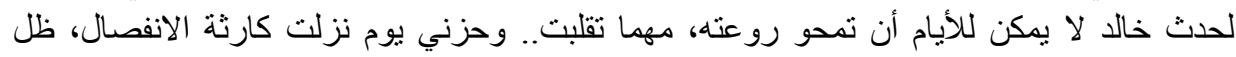

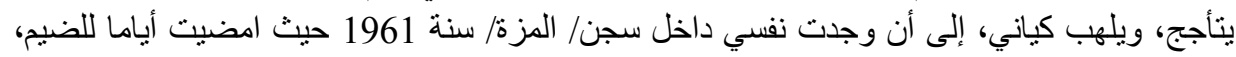

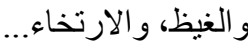

و إنني مازلت أذكر أعوام إقامتي في حلب الثهباء، ورأس العين، و القامشلي، و الحسكة، ودمشق الثقاء

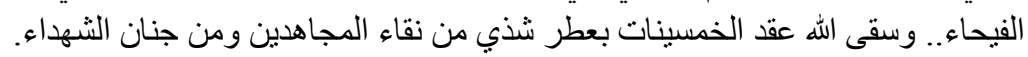

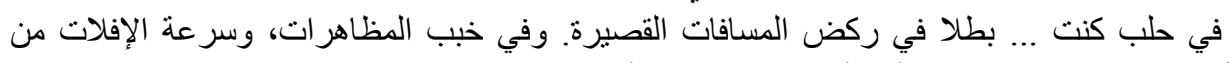

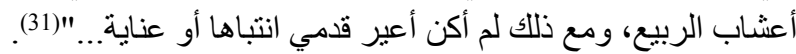

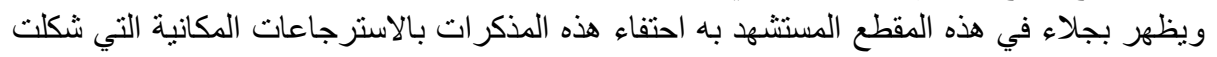

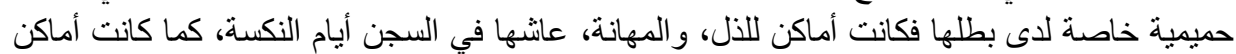

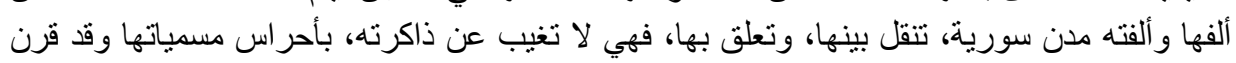

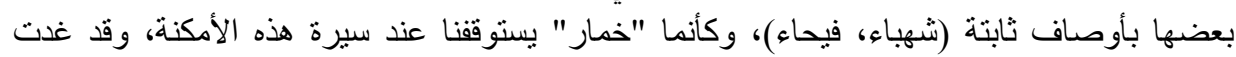

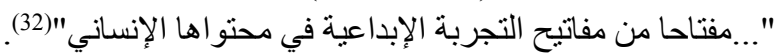

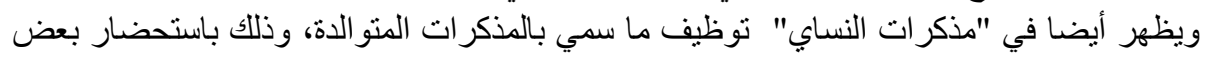

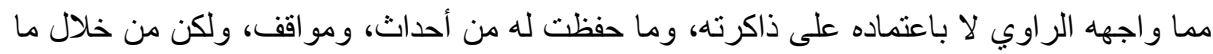

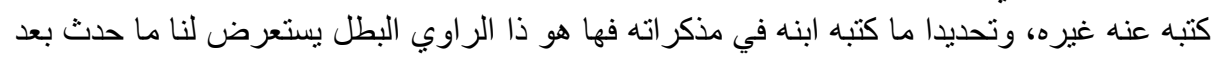

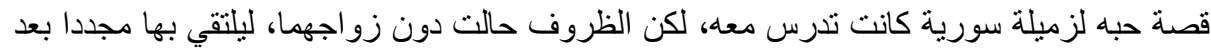

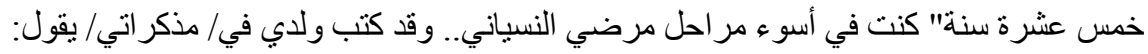

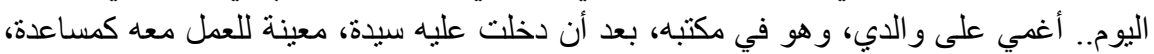

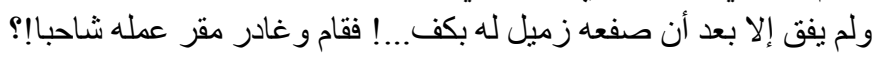

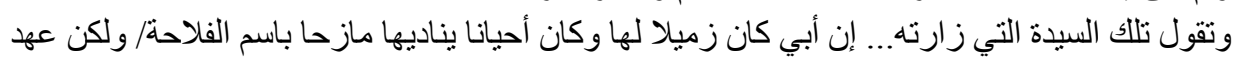

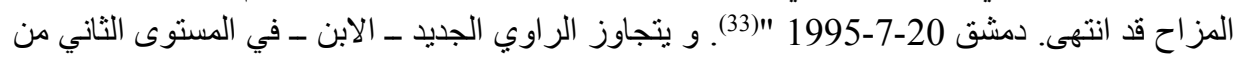

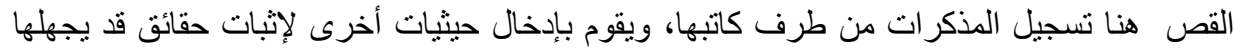

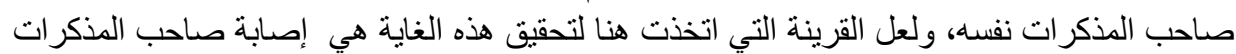

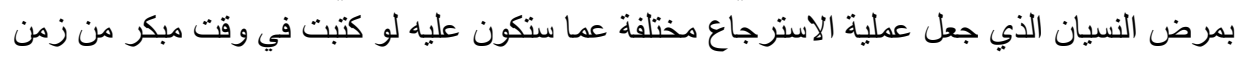


الكتابة الفعلي، ومما سبق نلاحظ أن المذكرات الذاتية بمكن أن نوظف المذكرات الغيرية، فينبثق عن

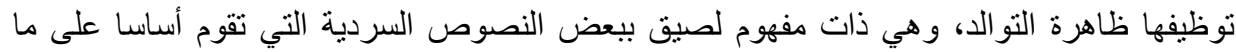

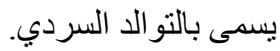

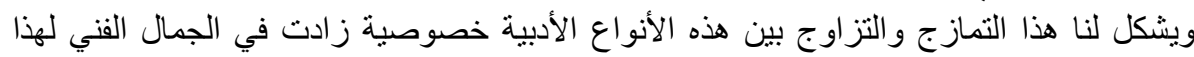

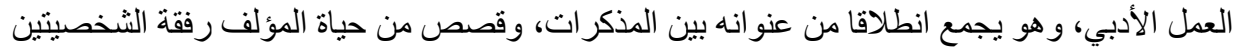

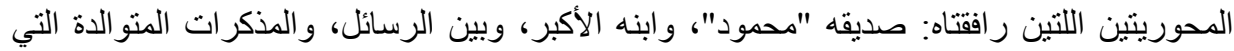

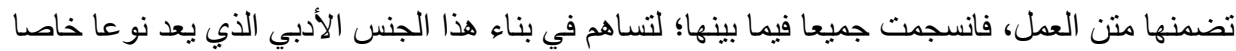

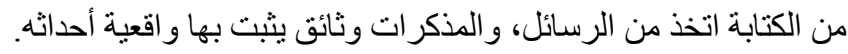

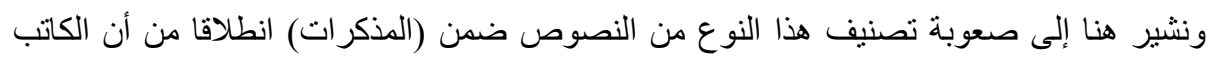

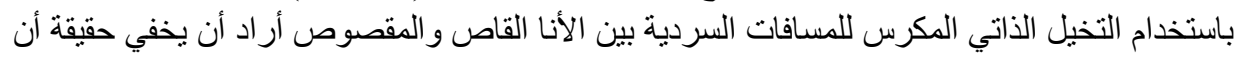

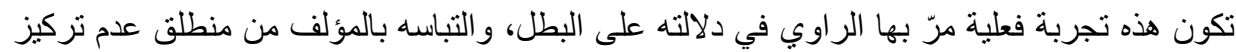

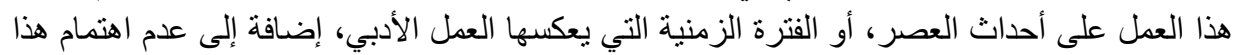

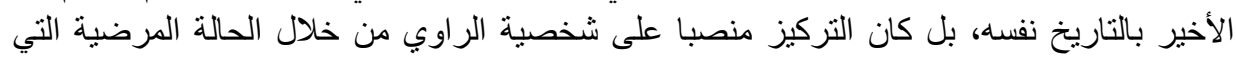

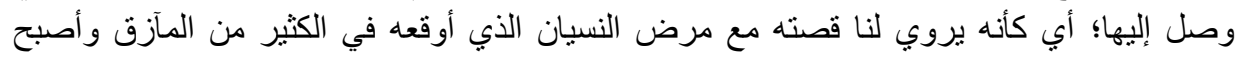

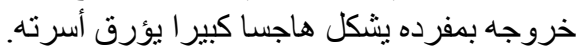

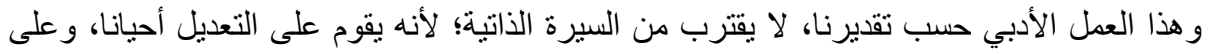

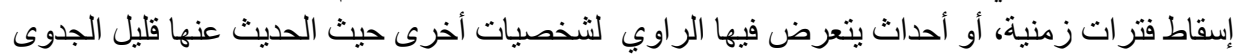

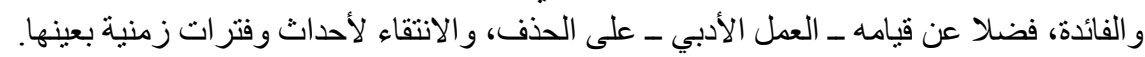

\section{4. تداخل المذكرات والخاطرة الذاتية في" لاجئ الحدود الثرقية في مذكرات}

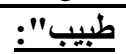

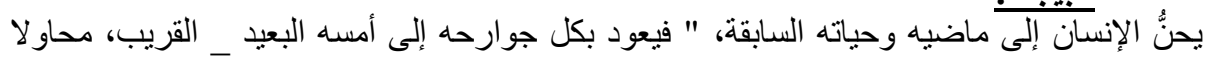

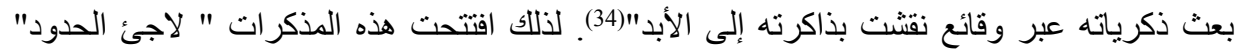

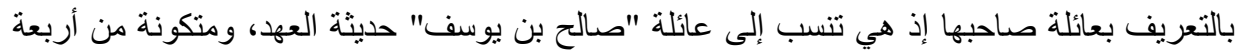

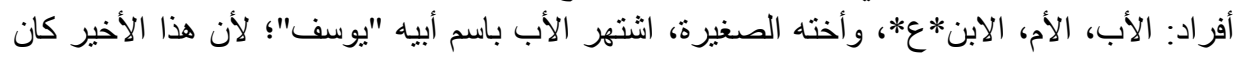

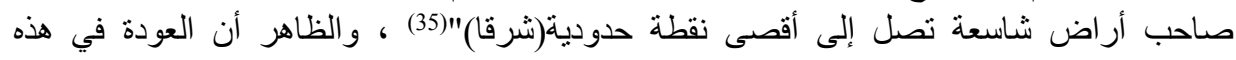

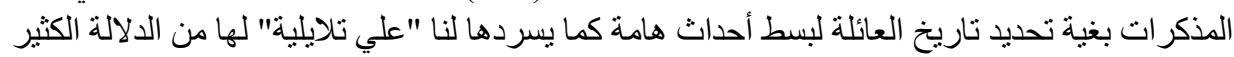

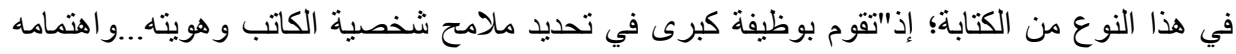

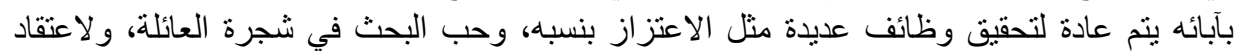

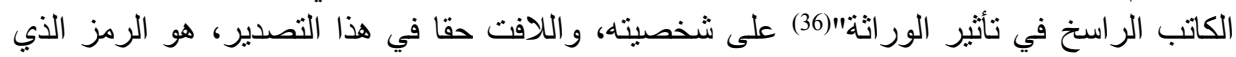

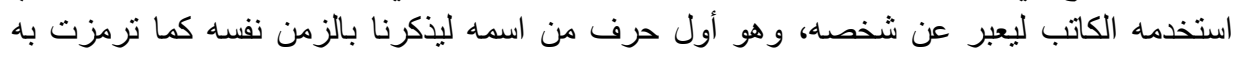

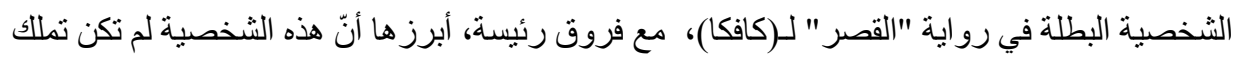

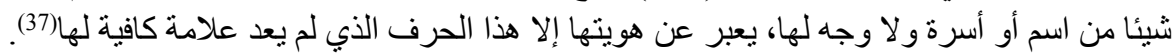

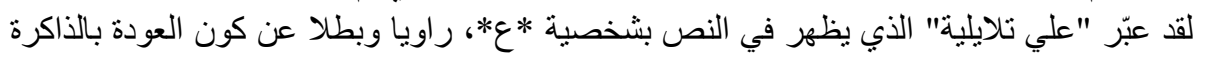

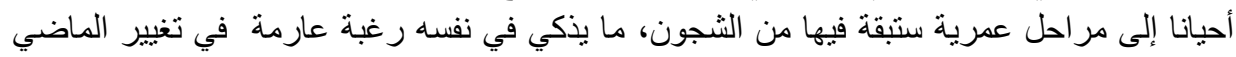

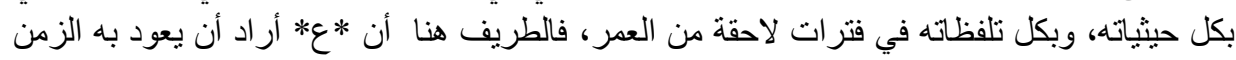

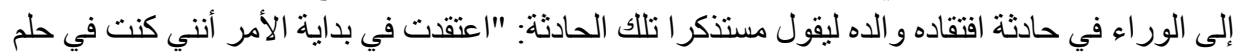




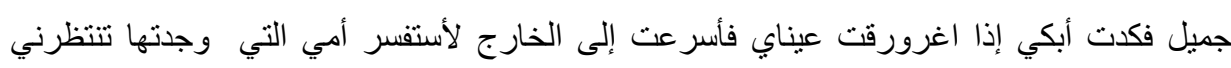

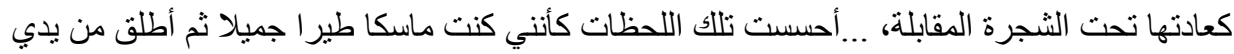

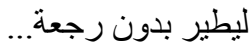
... لو كنت آنذاك بمثل عمري الآن (40 سنة)، لأتحفت سامعي بمثل هذه الكلمات:

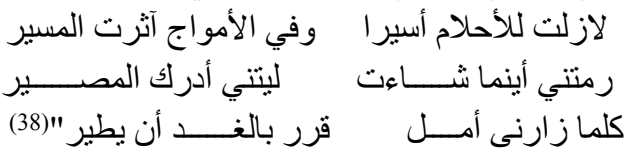

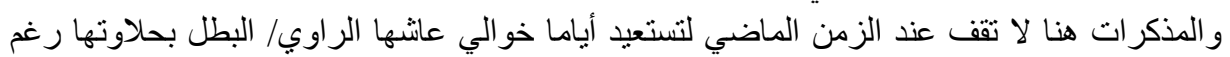

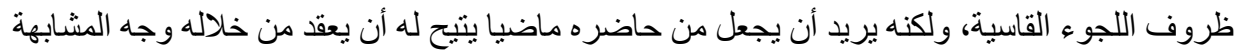

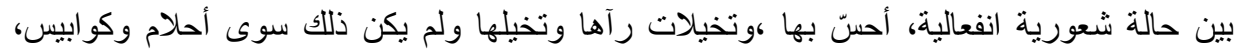

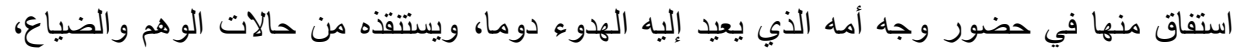

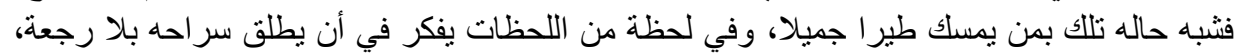

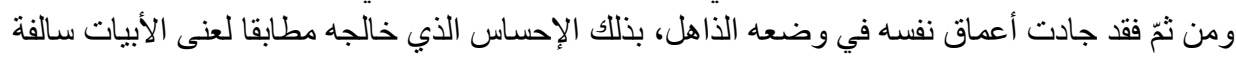

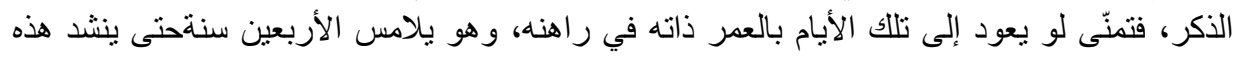
الأبيات التي طفح بها حاله. لقد كانت رغبة *ع* في إنثاد الثنعر بداية افتتاحية تبرز بها الموهبة الثانية بعد الكتابة النثرية، وهي التاني

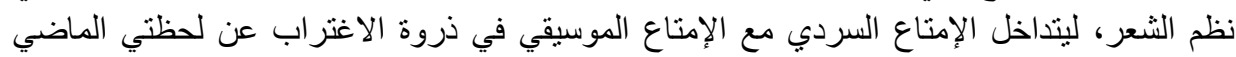
و الحاضر وهو يترجم لنا المقطع الآتي: " أخذني الحنين إلى ماض سحيقئ... وأنا أتجول بين محاسن قصر الحمر اء، غمرتني أحاسيس فياضة فكتبت إلى أحد الأصدقاء بالجز ائر مايلي:

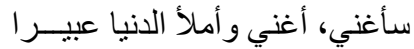

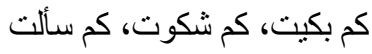

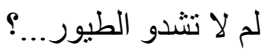

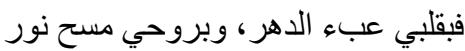

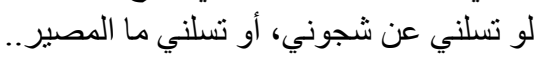

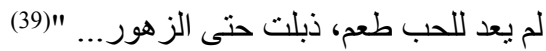

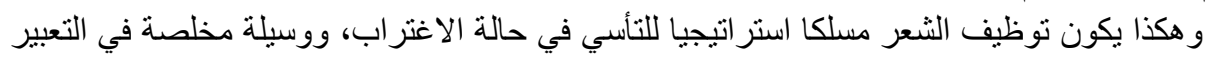

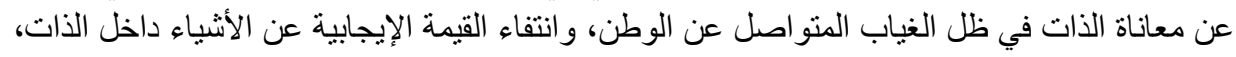

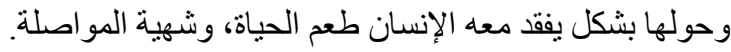

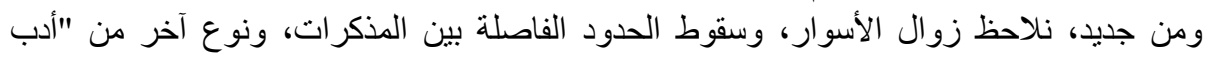

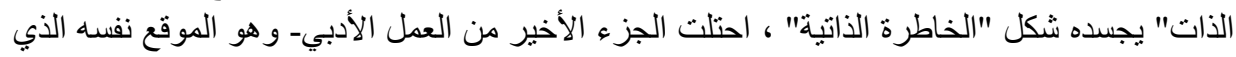

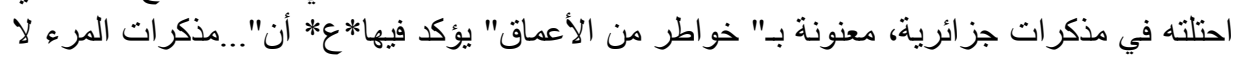

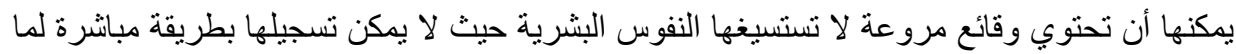

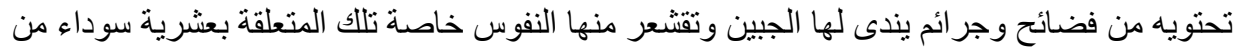

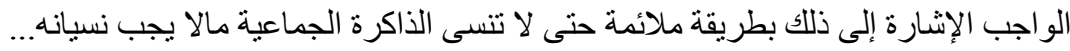

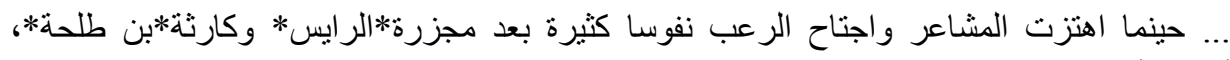

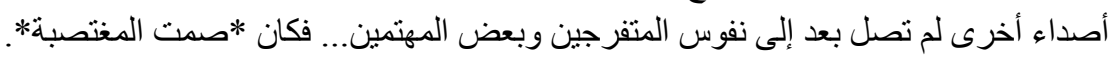




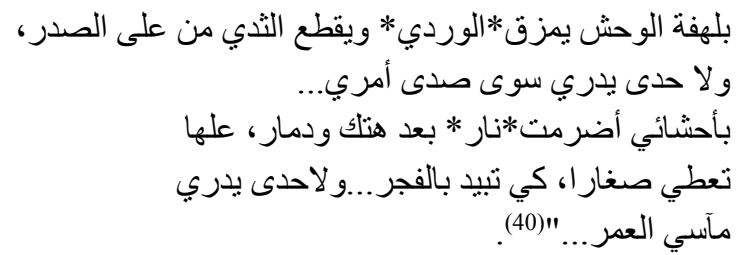

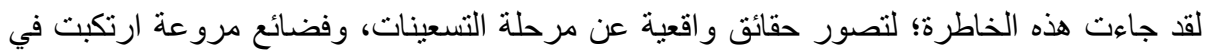

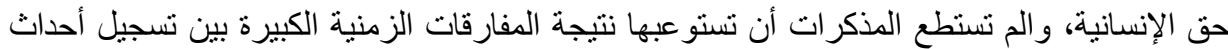

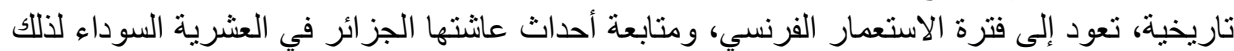

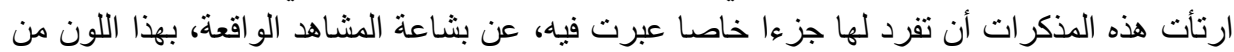
الأدب الذي يسمى " الخاطرة الذاتية".

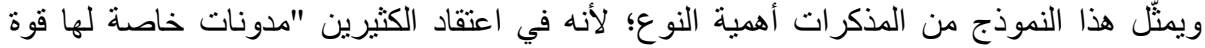

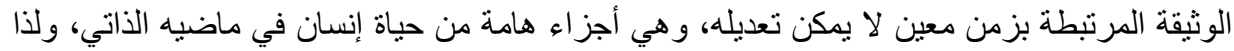

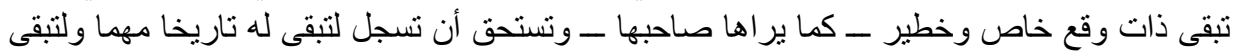

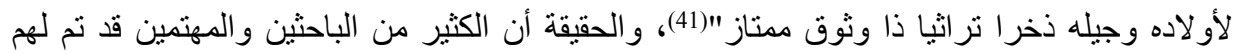

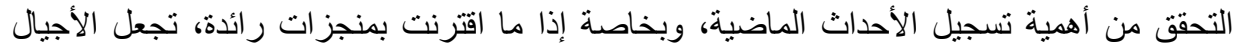

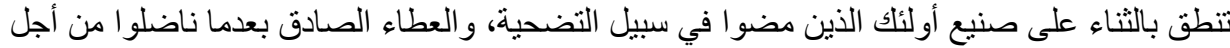
أن يعيش أبناء الجز ائر بكر امة في وطنهر.

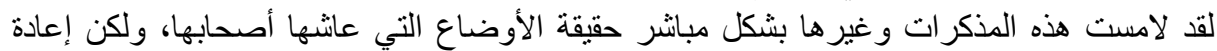

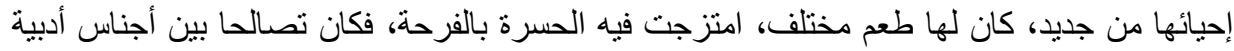

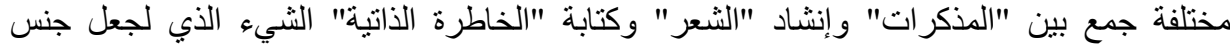
المذكر ات يتلون كل مرّة بلون مختلف. لئل

$$
\text { 5. التداخل بين المذكرات و اليوميات و والاعنر افات و والثعر و الرحلة وكتب }
$$

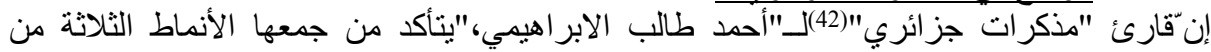

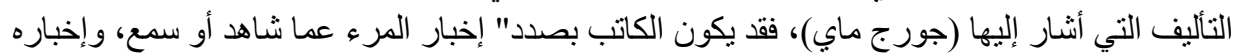

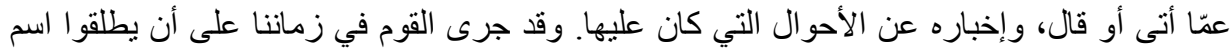

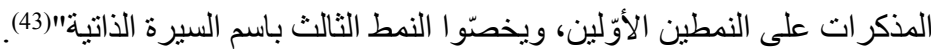

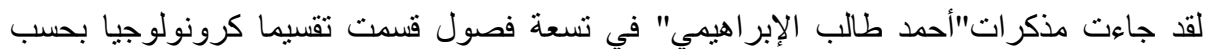

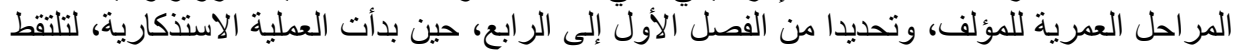

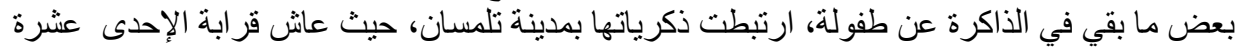

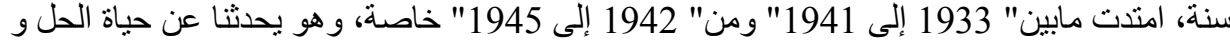

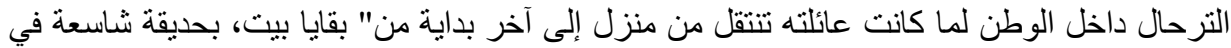

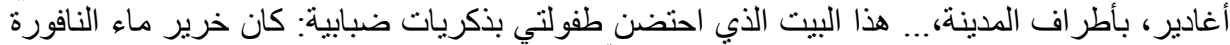

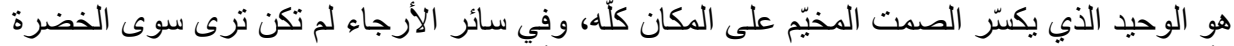

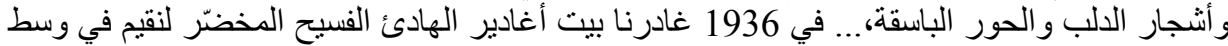
المدينة، بشار عبدي ابر اهيم، بالقرب من مسجد سيدي إبر اهيم المصمودي،...."(44). 
تلتحق بعدها أسرة "أحمد طالب" بمكان إقامة جبرية فرضتها الحكومة الفرنسية للشيخ الإبراهيمي

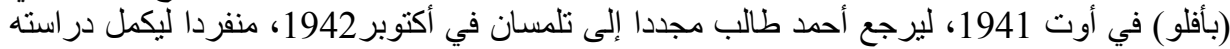

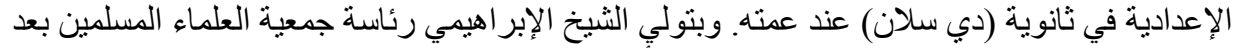

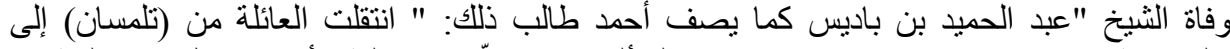

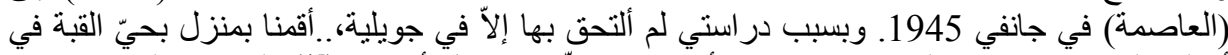

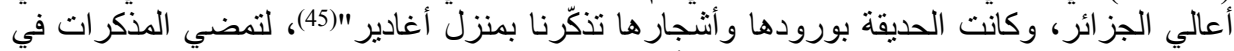

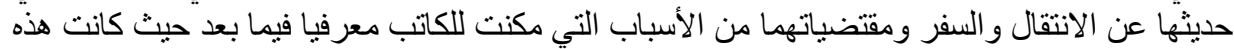

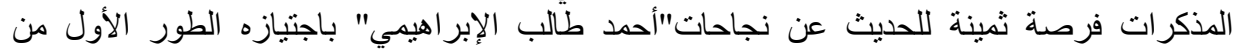

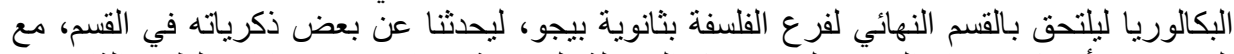

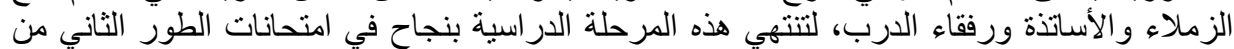

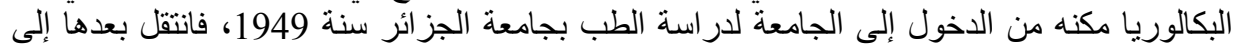

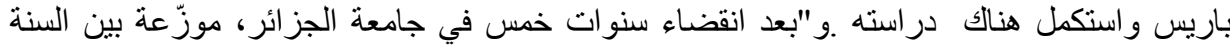

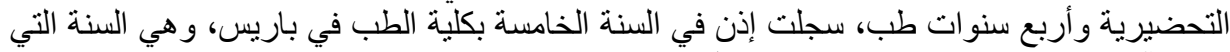

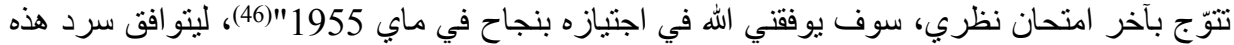

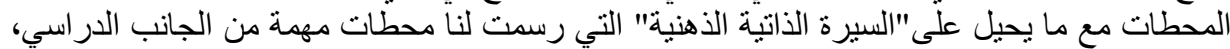

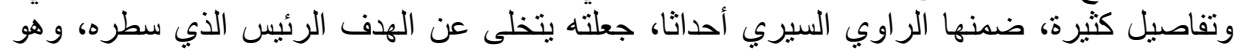

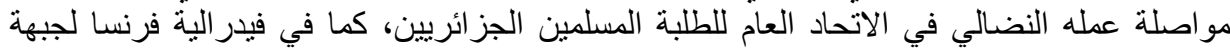

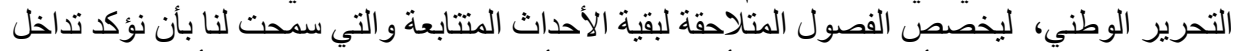

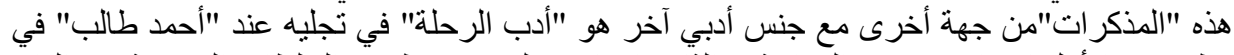

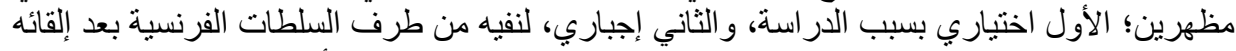

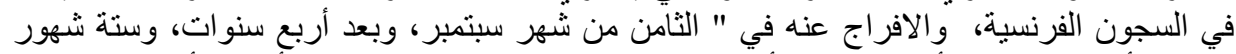

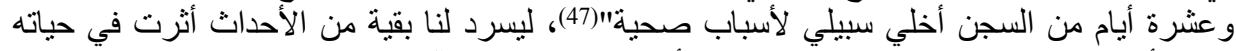

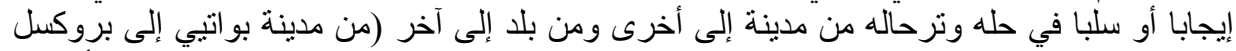

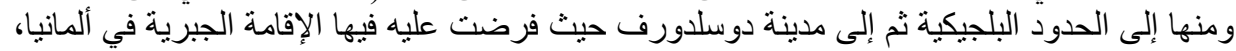

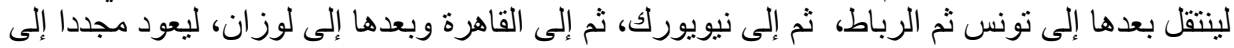

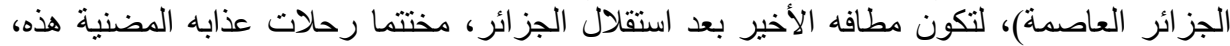

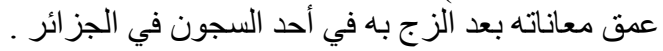

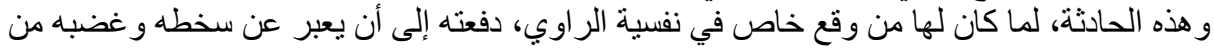

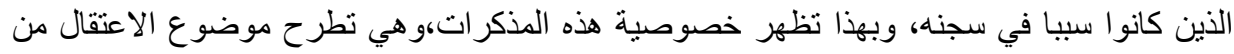

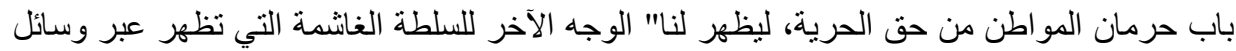

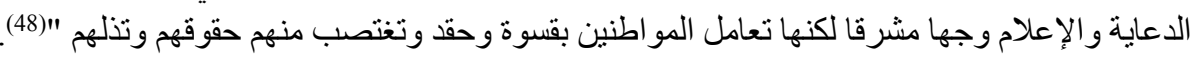

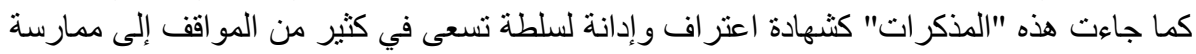

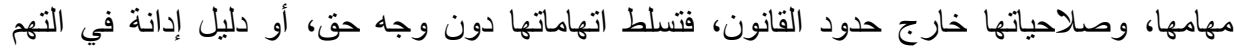

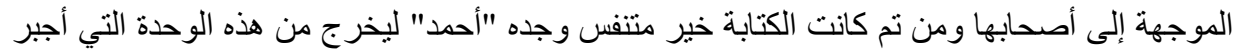

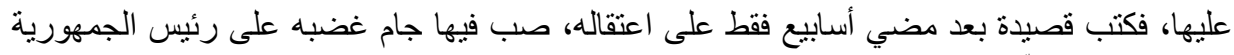

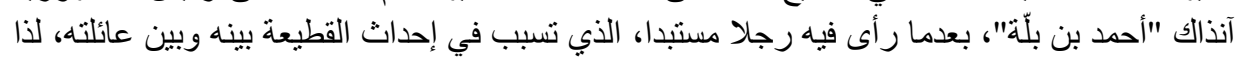
نعته بالطاغية. ومما جاء في هذه القصيدة التي شكلت لنا وجها من وجوه التداخل بين جنسي النتر و والثعر قوله: ولكنّي مازلت أنألم من خاصرتي ومن ذر أني 


$$
\begin{aligned}
& \text { و الدو اء مفقود } \\
& \text { فأصر خ تبا لبن بلّة المتعالي } \\
& \text { الذي نسي أن الله سبحانه وتعالى الكئل }
\end{aligned}
$$

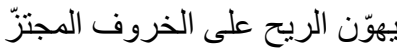

$$
\begin{aligned}
& \text { و أنه أكبر من كلّ الطغاة. } \\
& \text { السجن العسكري بو هر ان 09-09-1964 (49 النهاة. }
\end{aligned}
$$

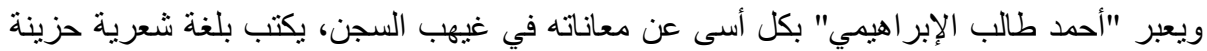

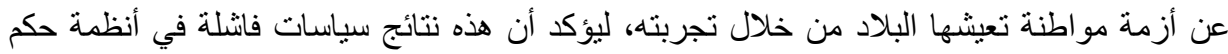

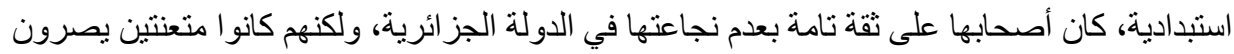

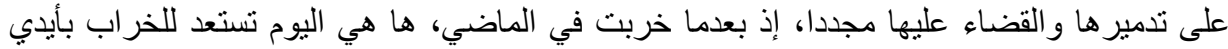

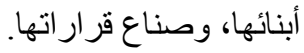

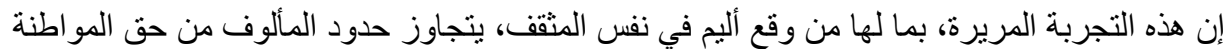

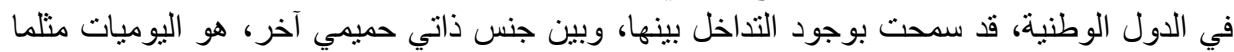

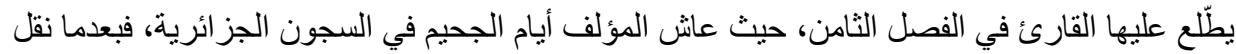

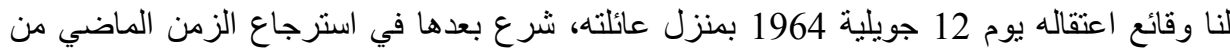

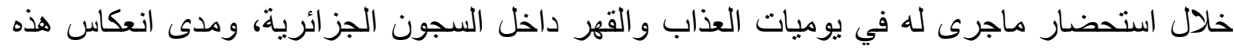

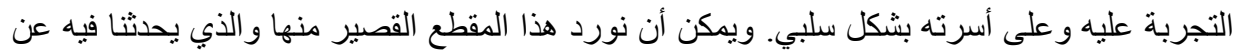

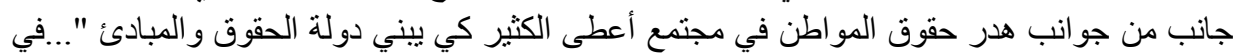

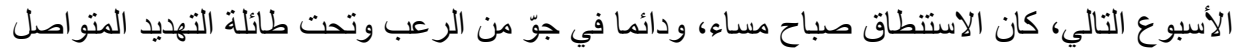

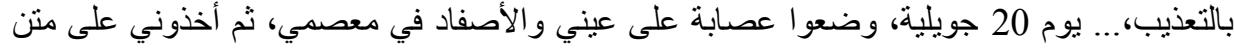

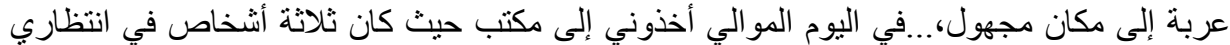

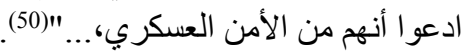

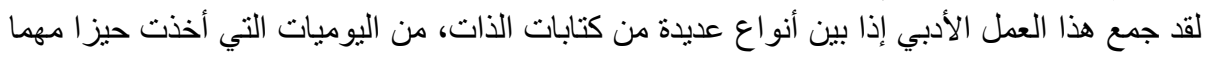

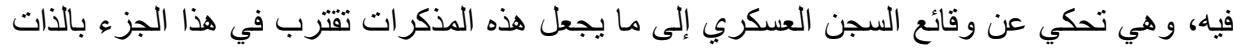

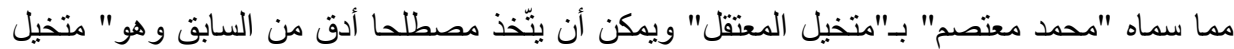

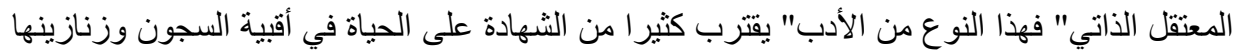

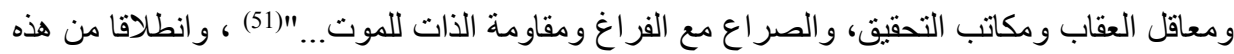

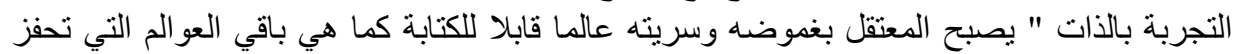

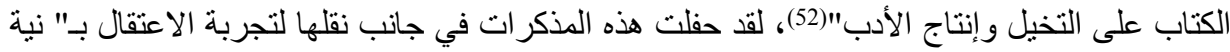

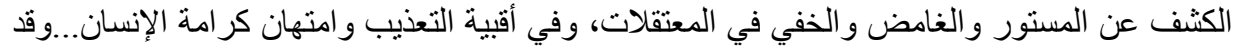

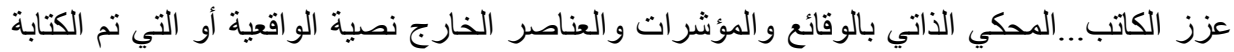
عنها: كالأمكنة و التو اريخ، و أسماء العلم، و الوقائع التاريخية والتئية والسياسية..."(53).

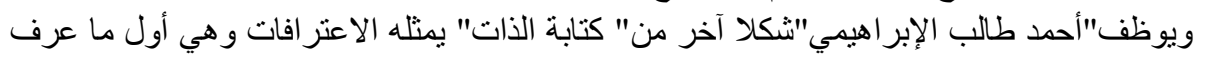

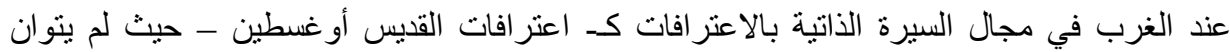

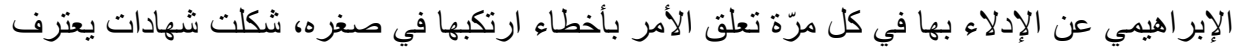

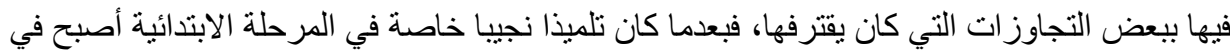

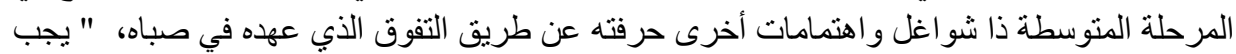




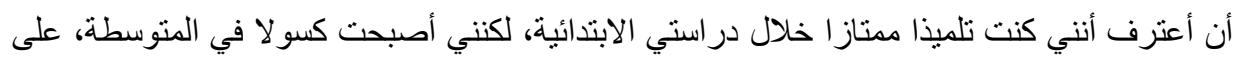

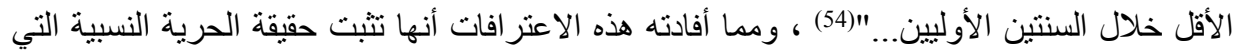

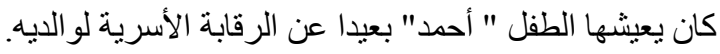

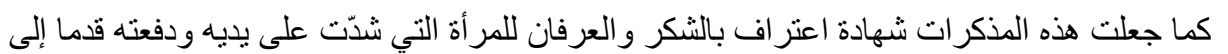

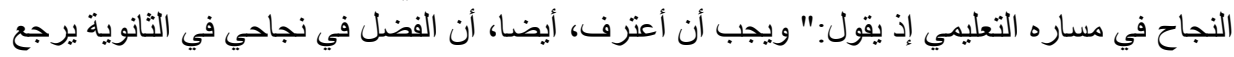

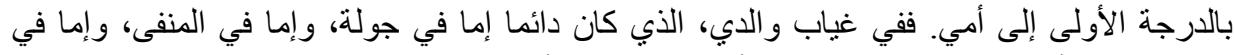

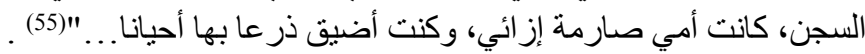

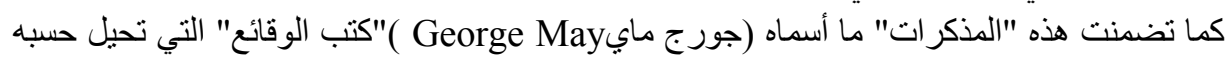

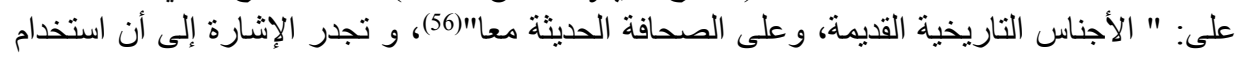

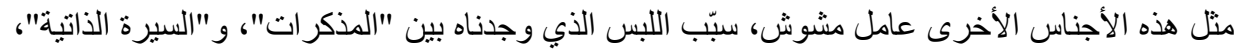

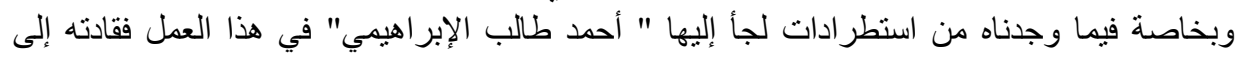

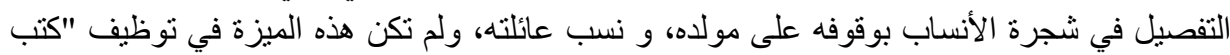

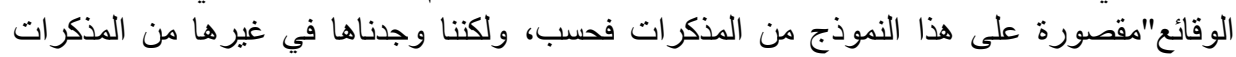

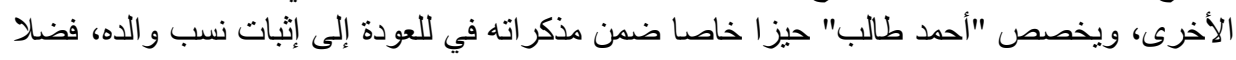

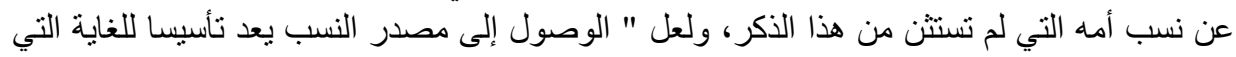

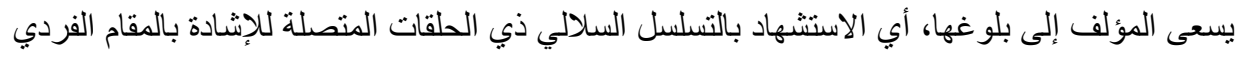

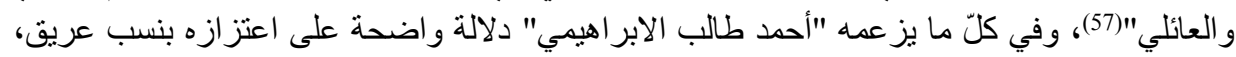

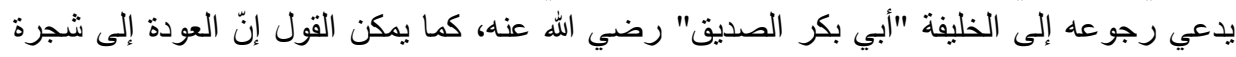

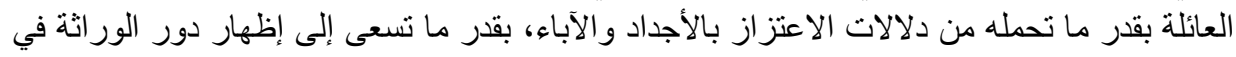

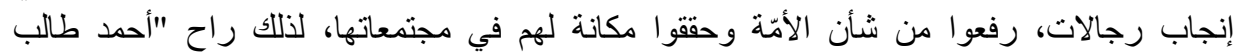

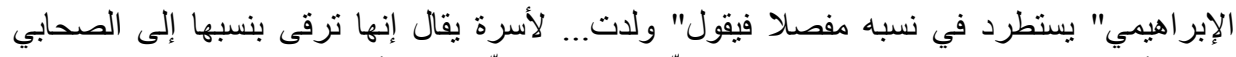

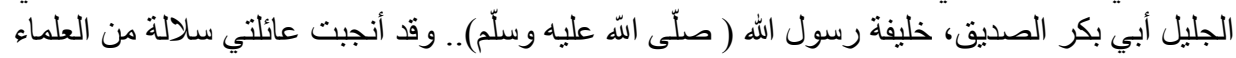

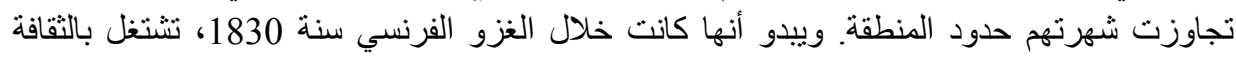

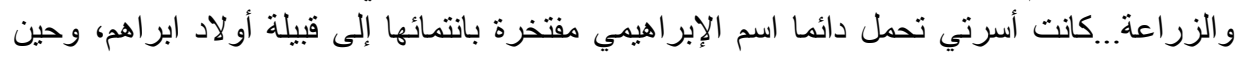

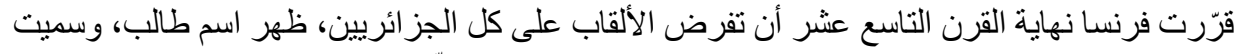

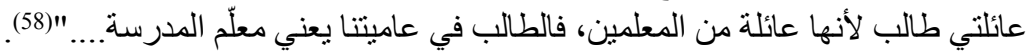

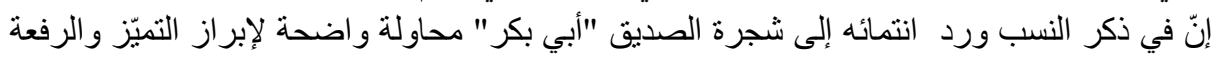

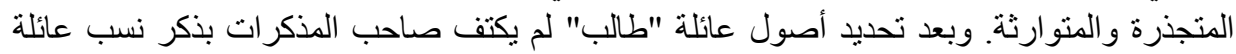

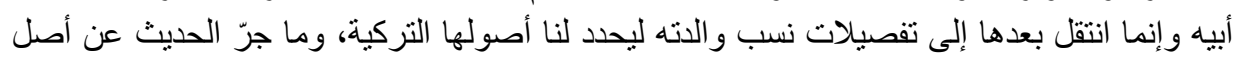

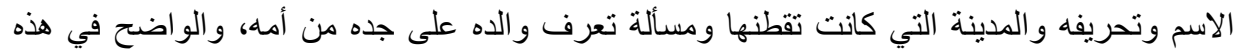

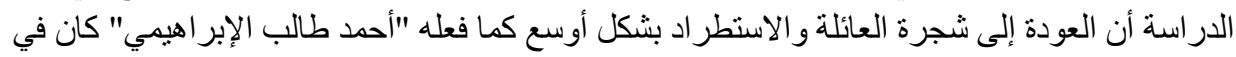

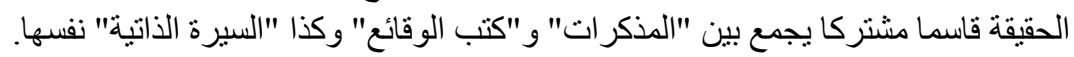

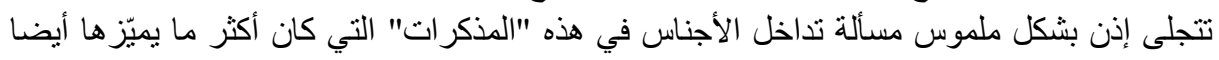

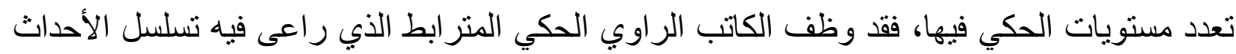

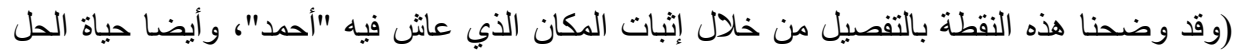

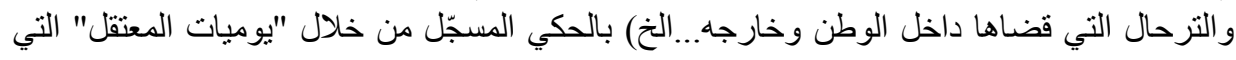


بناء على التحليلات السابقة، شكلت هذه النماذج الأربعة من المذكرات لزهور والبه ونيسي وبلقاسم خمار

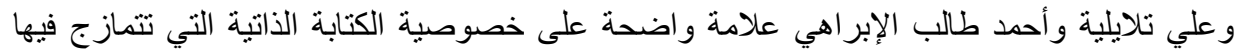

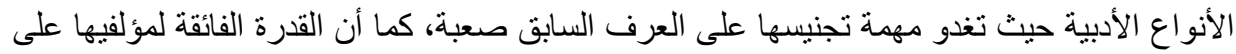

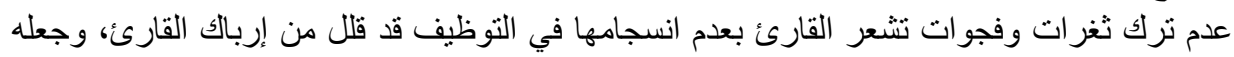

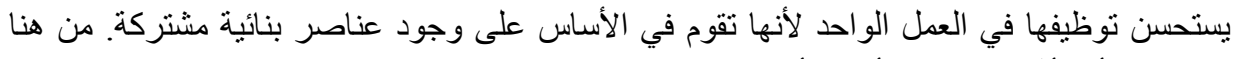

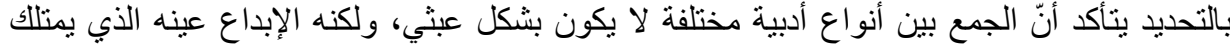

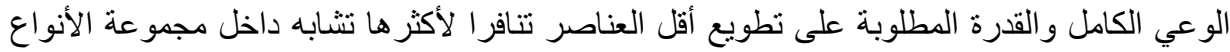

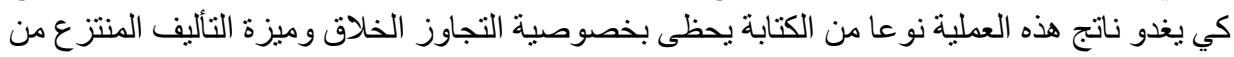

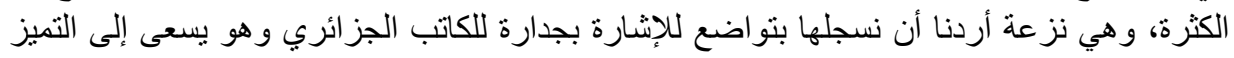

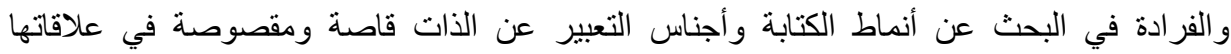
المتشابكة بالمجتمع و العالم الو اسع من ور ائه.

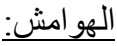

(1) -محمد الدّاهي : الحقيقة الملتبسة قر اءة في أثنكال الكتابة عن الذات، شركة النشر و التوزيع المدارس،

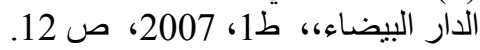
(2) -محمد الدّاهي : رقمنة الكتابة عن الذات، مقال ضمن علامات، العدد 30، ص 94 ـ.

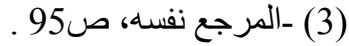

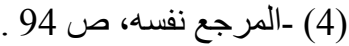

(5) - سلطان سعد القحطاني : التماس الفني بين السيرة الذاتية و الرو اية، مقال ضمن علامات، جمادى

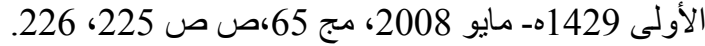

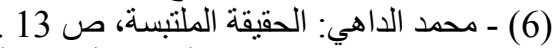
(7) - مجمو عة من المؤلفين:الأدب و الأنو اع الأدبية، ترجمة طاهر حجار ، تقديم محمود الربداوي، دار

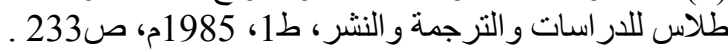

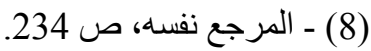

(9) - ز هور ونيسي: من يوميات مدرسة حرّة، مورفم للنشر ، الجزائر ، طبعة خاصة بعاصمة الثقافة

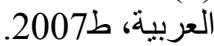

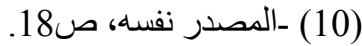
(11) - الدصدر نفسه، الصفحة نفسها. (12) -ينظر علي عبده بركات : رواد العيرة العاد الذاتية من إفرنج و عرب، مقال ضمن مجلة العربي،

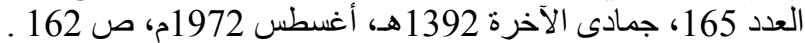
(13) - مذكر ات الثناذلي بن جديد، الجزء الأول:1929، 1979، منشور ات دار القصبة، 2012، ص

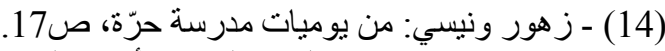

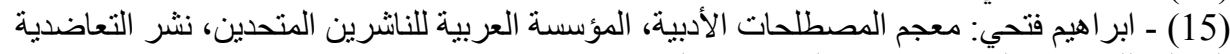

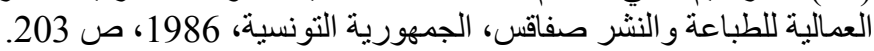
(16) - المصدر نفسه، الصفحة نفسئها. (17) -عبد العزيز شرف:أدب السيرة الذاتية، مكتبة لبنان، الثركة المصرية العالمية للنشر لونجمان،

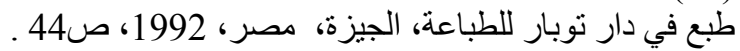
(18) ـاميل بديع بيعقوب، ميشال عاصي: المبرة المجم المفصل في اللغة و الأدب، دار العلم للملايين بيروت،

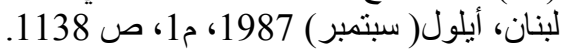


(19) - مجمو عة من المؤلفين: نظرية الأجناس الأدبية، تعريب : عبد العزيز شبيل، مر اجعة: حمادي

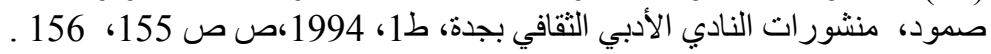

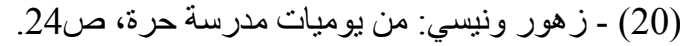

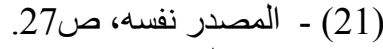

(22)- محمد بلقاسم خمار : مذكر ات النساي'الثشامية"..! ـو وقصص أخرى...، من منشور ات اتحاد الكتاب

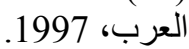

(23) -محمد صابر عبيد: تمظهرات التشكل السير ذاتيـ قر اءة في تجربة محمد القيسي السيرذاتية،

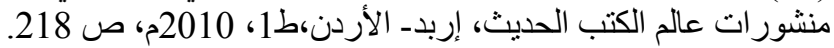

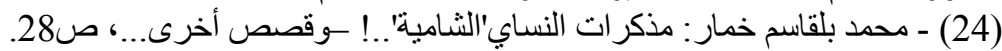

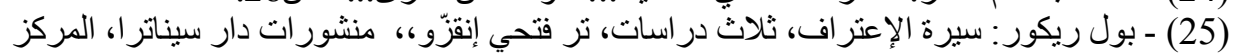

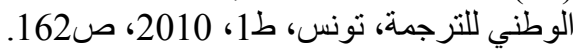

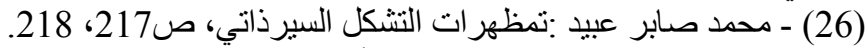

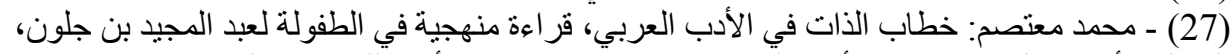

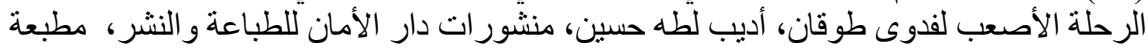

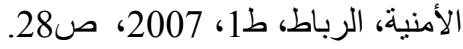

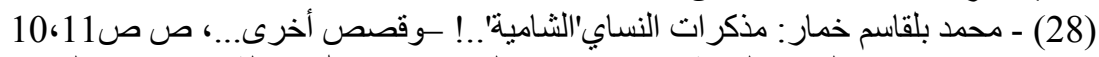

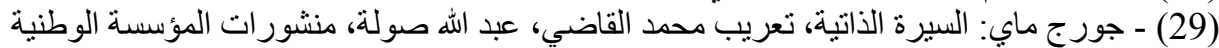

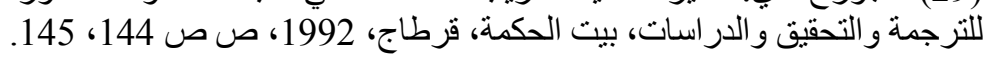

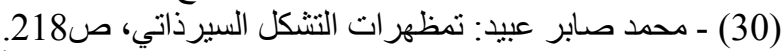

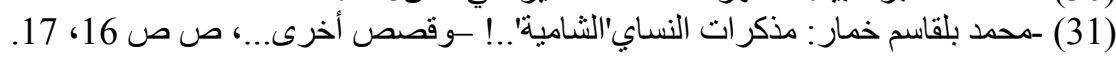

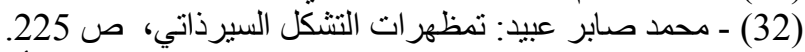

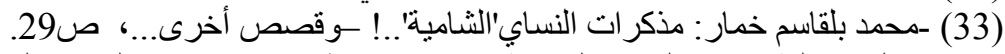

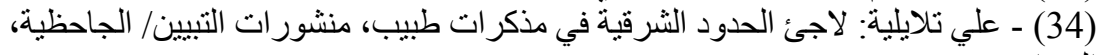

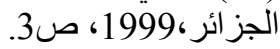

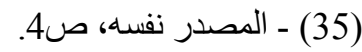

(36) - صالح مغيض الغامدي : كتابة الذات ـدر اسات في السيرة الذاتية-، منشور ات المركز الثقافي

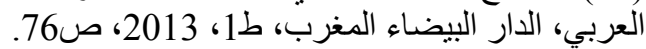

(37) - ينظر عبد الملك مرتاض: نظرية طابة الرواية بحث في تقنيات السرد، منشور ات عالم المعرفة،

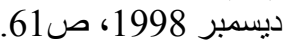

(38) - علي تلايلية: لاجئ الحدود الثرقية في مذكرات طبيب،208

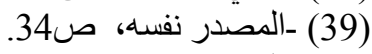

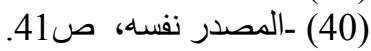

(41) - رياض الجابري: السيرة الذاتية و التراث *مقاربة نفسية*، منشور ات دار المعارف بحمص،

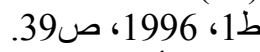

(42) - أحمد طالب الابر اهيمي: مذكر ات جزائري: أحلام ومحن(1932-1965)، دار القصبة،

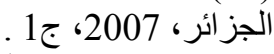

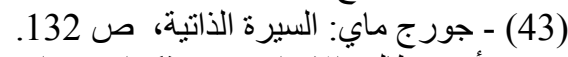

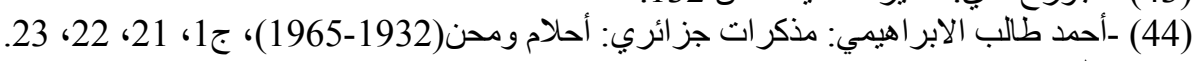

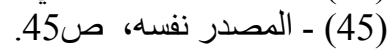

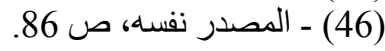

(47) - الدصدر نفسه، ص ص 149. 
(48) - محمد معتصم: المتخيل المختلف دراسة تأويلية في الرواية العربية الإنية

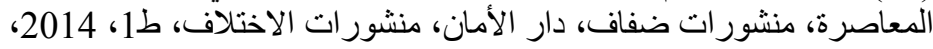

(49) - أحمد طالب الابر اهيمي: مذكرات جز ائري: أحلام ومحن(1932-1965)، ج1، ص204.

(50) - المصدر نفسه، ص الابر الهيدي.

(51) - محمد معتصم: المتخيل المختلف در اسة تأويلية في الرو اية العربية المعاصرة، ص115.

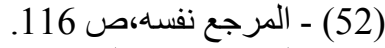

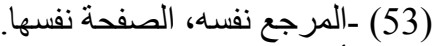

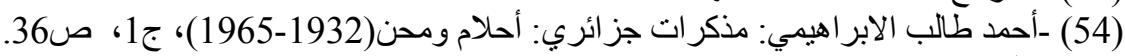

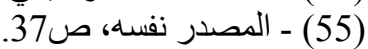

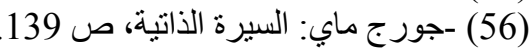

(57) ـعبد القادر الثشاوي: الكتابة والوجودــ السيرة الذاتية في الدغربـ، أفريقيا الثرق، الدغرب،

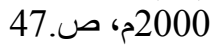

(58) ـ أحمد طالب الابر اهيمي: مذكرات جزائري: أحلام ومحن(1932-1965)، ج1،ص ص19، 